\title{
Los soportes hermaicos en Hispania: estudio sobre la funcionalidad y dispersión geográfica de los hermae epigráficos en la península ibérica
}

\section{In memoriam a Rosa M. Mercado}

\section{Hermae in Hispania: study of the function and geographic spread of the epigraphic hermae in the Iberian Peninsula}

El siguiente trabajo aborda el estudio de los soportes hermaicos de Hispania con la intención de ver hasta qué punto pudo extenderse este modelo epigráfico-escultórico, profundizando en sus aspectos de producción con el interés de identificar los talleres donde fueron creados. Para tal propósito se ha llevado a cabo un estudio de su funcionalidad, formas, materiales e inscripciones, acompañado de un catálogo -en formato de tablas comparativas-, que recoge todos los soportes para bustos hermaicos de Hispania, que permite el cotejo entre los diversos ejemplares. El objetivo final es poder reconocer la interacción entre materiales, lugar de hallazgo y funcionalidad en lo que respecta a este género de soporte escultórico.

Palabras clave: soporte hermaico, Hispania, culto doméstico, marmora locales, epigrafía.
This study examines the hermae supports from Hispania so as to determine the spread of this epigraphic-sculptural model and delve into aspects of its production so as to identify their workshops. Therefore, this research adopt a series of approaches based on the functionality, morphology, material and inscriptions of this supports. The study is completed by a catalogue - represented in the form of comparative tables - wich include all the epigraphic hermae supports of Hispania and alow their comparison. The aim is to determine the interaction between materials, location of discovery and function of this type of sculptural artefact.

Keywords: Hermae, Hispania, domestic cult, local marmora, epigraphy 
Los hermae hispanos han sido estudiados ampliamente, especialmente en lo que se refiere a los bustos que formaban parte de estos. ${ }^{1}$ Sin embargo, la ausencia de evidencia arqueológica en la península ibérica que permitiese la correlación de estos bustos con sus soportes provocó un vacat en el estudio de los pilares exentos que los sujetaban, de los que se conserva una nutrida colección. No fue hasta los estudios de Portillo, Rodríguez y Stylow (Portillo, Rodríguez y Stylow 1985) cuando estos soportes de hermae hispanos comenzaron a gozar de un cierto interés científico dentro del panorama de las producciones artísticas.

Aunque los estudios de Portillo, Rodríguez y Stylow arrojaron mucha luz hacia este tipo de soporte, creando el primer catálogo hispano, no pudieron tratar en profundidad las cuestiones físicas de estos hermae. Las novedades de estos últimos años, así como los actuales intereses en ámbitos de la investigación arqueológica, como son la arqueometría y el estudio de los materiales lapídeos, ofrecen la oportunidad para actualizar y profundizar en temas que entonces no pudieron ser abordados. Por este motivo, hemos afrontado el estudio de los pilares hermaicos en Hispania desde una aproximación a sus materiales, su producción y los talleres donde fueron producidos con el fin de poder reconocer la funcionalidad asumida por ellos y el marco geográfico en el que se erigieron. ${ }^{2}$

La finalidad de este trabajo es, por tanto, conocer la interacción entre la dispersión de este modelo epigráfico-escultórico concreto y los aspectos relacionados con su producción, es decir, la tipología material y sus características formales, para tratar, de este modo, de identificar, en la medida en que las evidencias lo permitan, los talleres que los produjeron. Para llevar a cabo tal propósito se ha realizado un catálogo completo con los cuarenta soportes de herma epigráficos documentados en Hispania.

1. Entre finales del siglo $\mathrm{xx}$ e inicios del siglo $\mathrm{xxI}$, los bustos de herma fueron los que despertaron mayor interés entre los investigadores. La identificación de los personajes y la edición de catálogos fue la tónica general de estos estudios (cf. Mayer 1999: 353-363). Los trabajos de Rückett de 1997 también contribuyeron de manera destacable, ya que sistematizó el repertorio de personajes, atendiendo a su cronología, el tipo de material empleado, labra, ubicación y funcionalidad. Dentro del panorama nacional, cabría destacar los estudios desarrollados en esta misma línea por Antonio Peña (cf. Peña 2018: 774-781; 2004: 271-289; 2000: 203-216), autor al que debemos una amplia bibliografía sobre el tema.

2. Este artículo es resultado de un trabajo realizado con el apoyo de la Unitat d'Estudis Arqueomètrics (UEA) dentro del proyecto Officinae lapidariae Tarraconenses. Canteras, talleres y producciones artísticas en piedra de la Provincia Tarraconensis (I+D HAR2015-65379-P MINECO/FEDER, UE), dirigido por la Dra. Diana Gorostidi Pi. Ha contado también con la financiación del Institut Català d'Arqueologia Clàssica (ICAC) a través de una de las Beques de introducció a la Recerca (BIR) y el apoyo de las Dras. Begoña Soler Huertas y Anna Gutiérrez Garcia-M. Por último, me gustaría agradecer a los dos evaluadores externos sus correcciones y comentarios que sin duda han ayudado a mejorar este trabajo.

\section{Contexto espacial y funcionalidad}

La reconstrucción arqueológica del contexto espacial y funcional de los hermae epigráficos hispanos ha sido posible fundamentalmente gracias a los ejemplos hallados en las excavaciones de la Plaza de España de Écija (Sevilla) (Rodríguez, Ordóñez y García-Dils 2008), en Porcuna (n.os $8,9,10,11$ y 12) y en la calle Blanco Belmonte de Córdoba (Ventura 1996) (n.os 31, 32, 33 y 25 del catálogo), los cuales han aportado importante información sobre su localización original. Del mismo modo, otras ciudades tanto del área gala (Jaillard 2001) como de la península itálica (Gavel 2011) - especialmente aquellas que fueros cubiertas por el Vesubio- han ayudado a conocer su contexto arqueológico original. Desgraciadamente, del resto de soportes hermaicos hispanos -es decir, del $80 \%$ de estos-, no hemos podido obtener un contexto espacial fiable, debido, bien a su reutilización en otras épocas posteriores, bien a su hallazgo por parte de personas ajenas a la arqueología durante la realización de labores agrícolas, o bien a causa del empleo de metodologías arqueológicas antiguas. ${ }^{3}$

No obstante, los datos a nuestra disposición permiten afirmar que la mayor parte de los soportes hallados en suelo peninsular se erigieron entre los siglos I y II d. C. Este fenómeno se desarrolló, por tanto, dentro de una coyuntura político-social iniciada por Augusto en la que se extendió el culto al genius del emperador. Dicha coyuntura produjo un paralelo en el ámbito doméstico, donde se comenzó a prestar una especial atención al genius del pater familias, conllevando la erección de bustos en conmemoración al genius o a la iuno de la familia (Corrales 2002; Schulz 2006; Pérez 2014). Se trata, por tanto, de un fenómeno propio del ámbito privado, integrante del programa decorativo de las domus tardorrepublicanas y altoimperiales, pero paralelo al que en la esfera pública vinculó el culto a los lares compitales con el del genius del emperador a partir de época augustea. ${ }^{5}$

Con el inicio del Principado, la erección de estatuas, gracias a las inscripciones que aparecían en sus soportes, se convirtió en el método propagandístico por excelencia; con ello, no solo destacaba la persona representada, sino que el dedicante de dicho monumento también ponía en relieve su nombre (Alföldy 1991). En el ámbito privado la erección de estatuas también tuvo un alto valor, no solo dentro del programa ornamental de las domus y villae con representaciones de divinidades y héroes, sino también como método de representación propia. Los hermae tuvieron, en este sentido, un papel indispensable siendo un soporte donde no solo se rendía homenaje

3. Como sería el caso del soporte conservado en el Museo Arqueológico de Granada, hallado en Martos (Jaén), reutilizado como umbral de acceso (cf. n. ${ }^{\circ} 14$ del catálogo).

4. En la mitología romana el genius era un ser o espíritu protector que nacía con la persona o cosa a la que iba ligado, y que tenía la misión de conservar la existencia de esta. No solo los hombres sino también las mujeres tenían su genius protector, en este caso denominado iuno (cf. Schulz 2006: 124125)

5. Sobre los lares compitales y su vinculación con el genius Augusti cf. Beard et alii 1998: 184-185. 
al dominus o la domina recordado, sino que también servía a los dedicantes, en su mayoría libertos o esclavos, como medio para su autorrepresentación (Peña 2000).

Los hermae, pese a poseer un origen votivo en sus primeras creaciones en época griega, en época romana evolucionaron hasta convertirse en unos soportes de tipo honorífico. Merece la pena recordar que, como nos han mostrado los ejemplos pompeyanos, los soportes hermaicos de ámbito privado se localizaban mayoritariamente flanqueando las puertas del tablinum de las domus o villae, en el atrio o peristilo de estas, por lo que serían visibles para todos aquellos que acudiesen a la casa del homenajeado (Dwyer 1991: 25-48). Por esta razón, se podría decir que en realidad todas tienen un cierto carácter público dentro de un ámbito doméstico, aunque, como veremos, existen excepciones en las que los pilares de hermae estuvieron expuestos en espacios públicos no domésticos.

\section{Modelos de difusión}

La presencia de los soportes hermaicos en Hispania no es un hecho aislado, sino que se engloba dentro de una práctica que ha sido documentada también en varias áreas de conocida influencia itálica, como en la desembocadura del Ródano en la Narbonense, el centro - particularmente en las ciudades de la Campania- y el norte de la península itálica - Transpadana.

Dentro de Hispania hemos podido comprobar como estos soportes solo se encuentran en ámbitos con unas características muy específicas - ciudades o territorios circundantes a ellas, las cuales poseían condición de colonia, muchas creadas para acoger a militares retirados y a otros ciudadanos latinos fundadas alrededor del siglo i a. C.- en un contexto enmarcado entre el siglo I d. C. y el II d. C. Como veremos, el formato de los soportes hermaicos hispanos no varía, sino que se mantiene igual durante toda su existencia y en todos los ámbitos geográficos.

Fijándonos en las otras áreas de difusión vemos ciertas variaciones; así, en la Narbonense, en Galia Cisalpina y Transalpina, y en la Transpadana, observamos cómo los soportes están mucho más trabajados que en la Bética y en la Campania, ${ }^{6}$ con presencia de molduras en la cara superior y delimitaciones del texto epigráfico, además de incluso decoración figurada. ${ }^{7}$ Una pauta común a todas las áreas es la utilización de materiales locales para su realización, aunque cabe mencionar el caso especial de los soportes antropomorfos de herma - de los cuales poseemos tres ejemplos en suelo peninsular, dos hallados flanqueando el tablinum de la domus II

6. Siendo aquí pilares troncopiramidales sin ningún tipo de decoración, con el campo epigráfico en su cara central raramente delimitado y, al igual que los béticos, con encajes rectangulares a sendos lados y un encaje superior para sustentar el busto.

7. La ausencia de evolución o cambio en estos soportes podría estar motivada por un intento de imitación de los soportes hermaicos de las zonas de origen — península itálicade los personajes representados, quizás por su asociación como elemento de prestigio o por el intento de remarcar su condición foránea. de Ampurias y otro en una domus de Cartagena- los cuales, pese a poseer una finalidad similar, estaban esculpidos en mármoles importados y carecían de inscripción.

\section{Delimitaciones espacio-temporales}

El corpus de los soportes epigráficos hermaicos de Hispania se encuentra integrado por cuarenta piezas, que se distribuyen dentro de la península ibérica en tres grandes zonas de condensación. Atendiendo al mapa de situación, la mayoría se sitúa en la Bética, dentro del arco formado por las ciudades de Astigi, Corduba y Obulco (el 75\% del total), más dispersos se encuentran los soportes hallados en Adra, Cádiz y Jimena, que representan un $7,5 \%$. Por otra parte, en la Lusitania solo se documentan cinco ejemplares en Augusta Emerita y dos en Pax Iulia, que juntos conformarían el 17,5\% de los soportes hispanos.

Para comprender mejor cada una de las características particulares y generales de estos soportes se ha realizado un catálogo completo y actualizado a partir de los estudios publicados en diversos trabajos (Rodríguez 1981; Portillo, Rodríguez y Stylow 1985; Encarnaçao 1984; García-Dils et alii 2006; Rodríguez et alii 2008), que en este artículo se verá resumido en forma de tablas de datos.

Tomando estos tres grupos principales como tres zonas de estudio diferenciadas podemos realizar las siguientes observaciones:

1. Según la zona de mayor densidad de soportes hermaicos (Astigi - Corduba - Obulco) podemos observar como el grueso de los testimonios se concentra en el valle del antiguo río Betis o cerca de sus afluentes, enmarcados por los sistemas montañosos Subbético y Penibético. En este ámbito geográfico contabilizamos 31 soportes hermaicos, lo que supone un $77,5 \%$ del total de soportes documentados en toda Hispania, todos ellos realizados en piedras calizas de tonalidades rojizas, muy compactas y de fácil pulido, dentro de las cuales podemos encontrar tanto variedades nodulosas o brechadas, como otras más compactas con presencia de recristalizaciones blancas de calcita (ver figura 2, n. ${ }^{\text {os }} 8-38$ y 40 ).

Dentro de esta amplia zona podemos hacer tres grupos teniendo en cuenta la concentración de los soportes hermaicos, estos grupos serían:

- Astigi y su territorio. El conjunto de soportes hermaicos hallados en este territorio representa el $22,5 \%$ del total hispano. ${ }^{8}$ En lo que respecta a su cronología es importante destacar este conjunto,

8. Astigi fue capital de uno de los cuatro conuentus iuridici y uno de los principales centros de producción agrícola de la Baetica (Colodrero 2006). La ciudad fue creada ex novo, rompiendo toda continuidad posible con el asentamiento turdetano anterior. Si observamos su urbanismo, las primeras actuaciones constructivas realizadas en la ciudad son un reflejo del contingente poblacional que participó en la deductio (González y Saquete 2011), veteranos militares de origen itálico — procedentes de las legiones IV Macedónica, VI Victrix y II Pansiana-, con presencia de especialistas cualificados y una destacable fuerza de trabajo asociada (Sáez Fernández et alii 2005). El origen de estos colonos tendrá un papel primordial en lo que se refiere a los soportes hermaicos como veremos más adelante. 


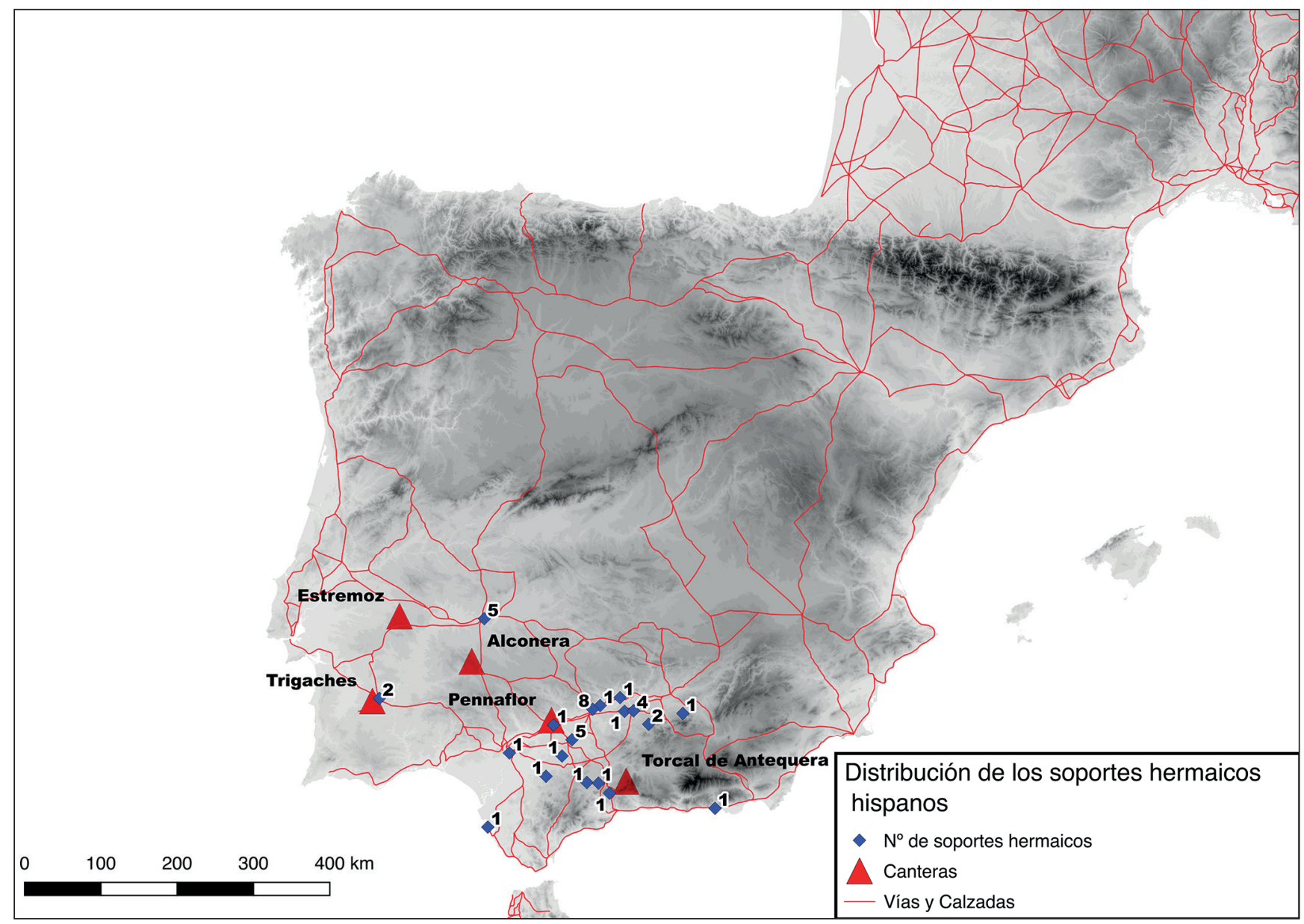

Figura 1. Mapa de distribución de los soportes hermaicos hispanos. ${ }^{9}$

ya que cinco de los ejemplares se sitúan en la primera mitad de siglo I d. C., constituyendo los primeros ejemplos de este tipo de soporte en Hispania; el resto están datados entre finales del siglo i y la segunda mitad del siglo II d. C. (García-Dils et alii 2006; Rodríguez et alii 2008; García-Dils 2009).

- Corduba y su zona de influencia. Los soportes hermaicos pertenecientes al territorio cordubense suponen el $25 \%$ del total de pilares de este tipo documentados. ${ }^{10} \mathrm{Si}$ prestamos atención a su cronología observamos cómo la mayor parte de estos soportes se enmarcan dentro del siglo I d. C., mientras que solo tres de ellos están situados en la primera mitad del siglo II d. C.

- Obulco y su hinterland (actual Porcuna). Los testimonios documentados en esta zona suponen un $20 \%$ del total de soportes hispanos. Los de la propia Obulco pueden ser datados, todos ellos, desde época de Augusto hasta inicios de época

9. Véase "Pennaflor" como Peñaflor.

10. Su situación estratégica hará de ella un enclave de destacada importancia durante la conquista romana. Cuando Augusto proceda a la deductio de la nueva Colonia Patricia, de veteranos de las guerras cántabras (González y Saquete 2011) - procedentes de la legio I Augusta-, y la puesta en marcha de un ambicioso programa urbanístico (Murillo 2013).
Flavia, cuando se amortiza el "barrio romano" (actual San Benito), lugar de procedencia de la mayor parte de estos soportes. Mientras que los pertenecientes a su zona de influencia (n. ${ }^{\text {os }} 13,14$ y 15), debido a la ausencia de contexto arqueológico, solamente son datables a partir de sus características paleográficas, lo que amplía su horquilla cronológica hasta mediados del siglo II d. C. ${ }^{11}$

- El 10\% de los soportes restantes se corresponden con los ejemplos dispersos dentro del ámbito de influencia de las ciudades. Algunos de estos fueron hallados en diversas zonas rurales posiblemente correspondientes a antiguas villas, muestra de ello serían los ejemplos n. ${ }^{\text {os }} 38$ y 40, hallados en Adra (López Medina 1996) o Jimena (Ramírez González y Sánchez Velasco 1995), y otros como el n. 39 hallado en Cádiz

11. En el siglo III a. C. comenzó la romanización de la ciudad túrdula Ibolca, que pasará a denominarse Obulco, en el siglo I a. C. A finales de este siglo, participará en la Guerra Civil manteniéndose fiel al bando cesariano, tras lo que se producirán dos hechos clave, la municipalización y colonización del territorio con la concesión del Ius Latii y la creación de una colonia de ciudadanos latinos y romanos, con lo que se culmina la "romanización" de esta zona (González y Saquete 2011). 
Laura Galán Palomares, Los soportes hermaicos en Hispania: estudio sobre la funcionalidad y dispersión geográfica de los hermae...

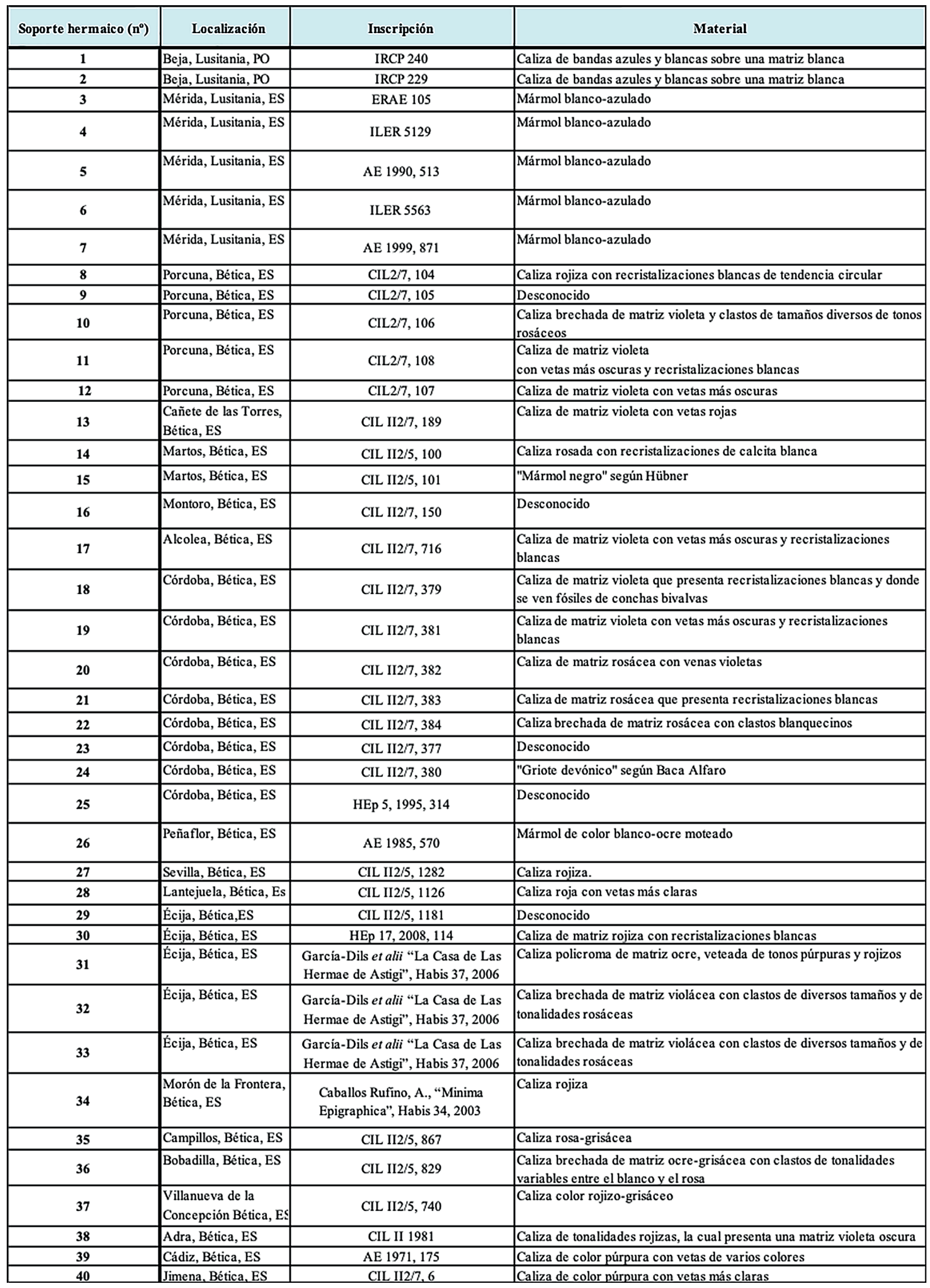

Figura 2. Soportes hermaicos documentados en territorio hispano. 
y en otras ciudades de la Bética. Sus cronologías abarcan desde mediados del siglo i d. C. hasta prácticamente el primer tercio del siglo II d. C.

2. Si nos desplazamos hasta el segundo punto de concentración, tenemos que situarnos en la capital de la Lusitania, Augusta Emerita. ${ }^{12}$ Los pilares de herma localizados en este contexto geográfico suponen un 12,5\% del total hispano. Todos ellos están realizados en un mármol blanco-azulado (ver figura 2, n. ${ }^{\text {s }}$ 3-7). Este conjunto está datado cronológicamente entre el primer cuarto del siglo i d. C. e inicios del siglo II d. C. Dentro de este grupo se han documentado ejemplos de hermae procedentes de contextos públicos —como sería el ejemplo n. ${ }^{\circ} 6$, hallado en el peristilo del teatro-, así como uno, el n..$^{\circ}$, que, al contrario de lo esperable, manifiesta una clara funcionalidad funeraria.

3. El último conjunto de soportes hermaicos localizados en la Lusitania lo encontramos en la ciudad de Pax Iulia. ${ }^{13}$ Los soportes hermaicos hallados en este contexto geográfico están realizados sobre un mármol blanco con bandas azul-grisáceas de muy buena calidad (ver figura 2, n. ${ }^{\text {os }} 1$ y 2). El conjunto de estos solo supone un 5\% del total de los pilares hermaicos catalogados, pero su realización en un material diferente al resto de los conjuntos hace que lo consideremos como un grupo diferenciado. La cronología de estos está acotada en el siglo I d. C.

Con todo esto, podemos ver cómo las tres zonas de concentración comentadas tienen ciertas similitudes, como su origen en época cesariana o su fundación en época de Augusto y su situación como asentamiento de veteranos o zona de migración itálica.

\section{Los materiales utilizados: definición tipológica y distribución geográfica}

Frente a lo que cabría esperar, dado el apogeo de estudios sobre los marmora hispanos que se han llevado a cabo durante los últimos años, el estudio de los materiales lapídeos empleados como soporte epigráfico dista mucho de estar consolidado. ${ }^{14}$

Solo el catálogo de inscripciones romanas del conuentus Pacensis (Encarnação 1984) —en el marco del auge de la reivindicación sobre la importancia del

12. Fundada por Augusto en el año 25 a. C., pocos años después del comienzo de las Guerras Cántabras para asentar a los veteranos — de las legiones $V$ Alaudae y X Gemina- procedentes de esta confrontación (Dupré 2004).

13. Situada en el tercio sur de la provincia lusitana, la Civitas Pacensis fue una colonia y capital de un convento jurídico. Su origen se sitúa antes del año 27 a. C., cuando Augusto le concedió el título de colonia al asentamiento surgido del campamento instalado por Julio César, de quien habría obtenido el ius Latii (Fabião 2014).

14. En el estado actual de nuestros conocimientos, las conclusiones derivadas del análisis del soporte material son por el momento limitadas y también están condicionadas por la ausencia de determinaciones arqueométricas. En este sentido, las reflexiones planteadas respecto a la tipología material y sus canteras de procedencia deben ser tomadas con cautela, las cuales deberán ser refrendadas o modificadas a medida que avance la investigación y se proceda al análisis arqueométrico del conjunto. soporte epigráfico- ofrece una información solvente respecto al material sobre el que se realizaron las inscripciones latinas del territorio mencionado. Por otra parte, en lo que respecta a las inscripciones de carácter hermaico, el catálogo realizado en 1985 por Portillo, Rodríguez y Stylow ofrece una línea a seguir en cuanto al origen material de estos soportes. No obstante, y como resultado del avance de la investigación en la identificación de canteras y materiales en sus distintos ámbitos de procedencia, dichas aportaciones quedan relegadas a una simple aproximación.

\section{Tipología macroscópica de los materiales}

En cualquier caso, la recopilación de todas las referencias relativas a la tipología material del conjunto de soportes hermaicos hispanos y su cotejo con los focos extractivos documentados dentro de los límites territoriales de procedencia ha permitido realizar una primera aproximación, desde la observación macroscópica, sobre la tipología material empleada y sus principales fuentes de aprovisionamiento. De este modo, hemos podido identificar los siguientes tipos de materiales:

\section{Mármol de grano medio, de color blanco, o blanco-gris bandeado, muy compacto y uniforme.}

Los hermae realizados en este material (n. ${ }^{\text {s }}$ 3, 4, 5 y 7) presentan un suave pulido, así como una buena conservación general del material. Todos los soportes realizados en este tipo de mármol (ver figura 8) pertenecen al ámbito geográfico de Augusta Emerita, razón por la cual, y tomando en consideración la descripción macroscópica de la roca, así como su localización geográfica, podría adscribirse a la tipología litológica del Anticlinal de Estremoz. ${ }^{15}$

Los mármoles del Anticlinal de Estremoz presentan colores variados y suaves. Predominan los blancos con algunas vetas rosadas procedentes de la zona de Estremoz, aunque también se documentan variedades de color blanco-rojo, rojo, rosado, verde, gris y blanco-gris bandeado (Mañas 2011a). A este último tipo correspondería el material empleado en la mayor parte de los soportes hermaicos estudiados. Con el paso del tiempo las variedades blancas adquieren una pátina característica de color ocre.

Según diversos autores (Álvarez et alii 2009; Taylor et alii 2017), las canteras del Anticlinal de Estremoz actuarán como la principal fuente de aprovisionamiento de rocas ornamentales de Augusta Emerita desde su fundación en el año 25 a. C., empleadas en la labra

15. El Anticlinal de Estremoz se localiza en el sector septentrional de la zona de Ossa Morena, en el Macizo Hespérico. Tiene una forma alargada de $40 \mathrm{~km}$ de largo por $7 \mathrm{~km}$ de ancho (Lamberto y Sá 2009). La explotación de los mármoles de esta zona se encuentra atestiguada desde época romana, de la que se conservan diferentes frentes de explotación en canteras repartidas en los distritos de Estremoz, Borba, Vila Viçosa y Pardais (Álvarez et alii 2009; Lapuente et alii 2014; Taylor et alii 2017). 

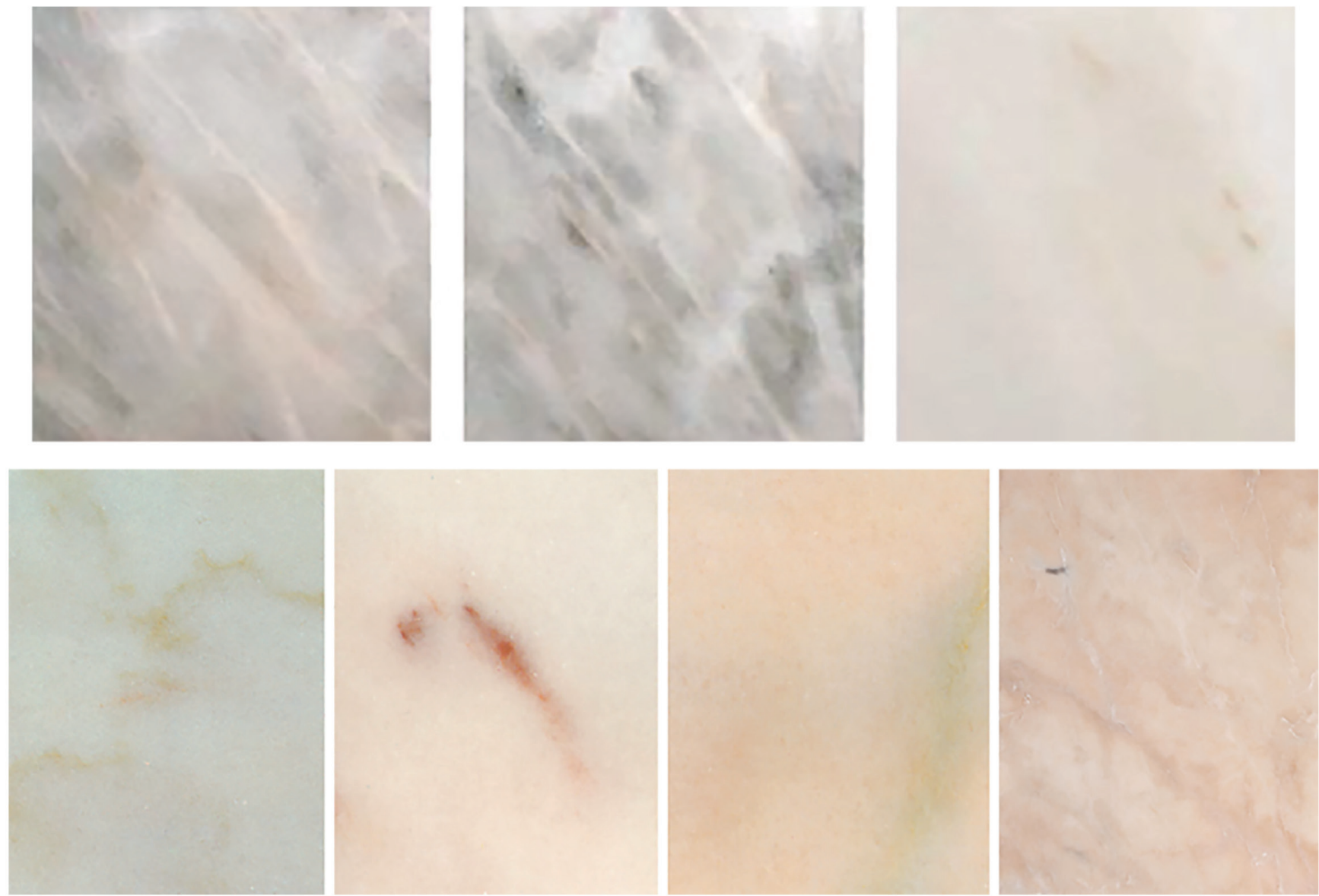

Figura 3. Diferentes variedades del mármol procedente del Anticlinal de Estremoz (fotografías de la autora).

de los primeros retratos y epígrafes datados en época augustea (Lapuente et alii 2014).

Un caso excepcional sería el soporte n. ${ }^{\circ}$ 6. Pese a pertenecer a este ámbito, su material presenta unas características macroscópicas diferentes, semejantes a un cipollino. Se puede describir como un mármol cristalino con masa de fondo que va del blanco al verde muy claro, las vetas de color verde oscuro son sutiles y ondulantes. Sin embargo, no es posible corroborar la identificación concreta ya que no se ha podido extraer una muestra. ${ }^{16}$

\section{Mármol de grano grueso, de color grisáceo con vetas azuladas, muy compacto y uniforme}

Los hermae realizados en este material (n.os 1 y 2) presentan un buen grado de pulimentación, lo que unido a su dureza hace que los soportes hayan conservado sus cualidades físicas hasta la actualidad. Todos los pilares hermaicos realizados en este material (ver figura 8) pertenecen al ámbito geográfico de Pax Iulia, por lo que, si tenemos en cuenta la

16. Queda pendiente el análisis arqueométrico, que esperamos poder realizar en un futuro en el seno de la Unidad de Estudios Arqueométricos (UEA) del ICAC. descripción macroscópica del material, así como su localización geográfica, pueden ser adscritos a las canteras de Trigaches. ${ }^{17}$

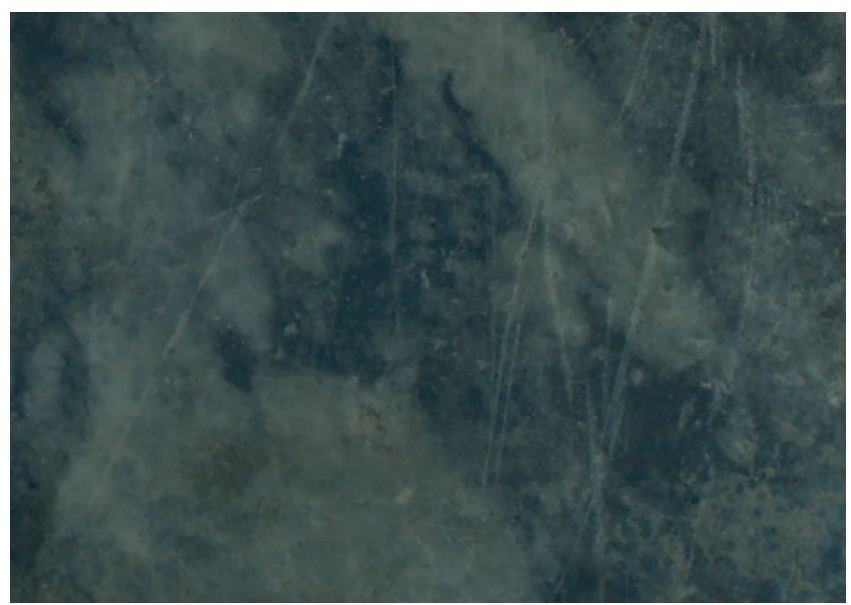

Figura 4. Mármol de Trigaches (fotografía de la autora).

17. La cantera de mármol de Trigaches se localiza en el área de Beja, municipio de Trigaches, en la parroquia de São Brissos en el lugar llamado Herdade do Monvestido; en el Alto Alentejo. Geológicamente se define como un mármol gris y fétido, de grano medio o muy grueso y bandeado en tonos grises (Cisneros et alii 2011). La explotación de estas canteras, 
Los mármoles de Trigaches se encuentran entre los más versátiles, usados y difundidos de la Lusitania romana. Este tipo de mármol fue usado de forma masiva en Pax Iulia, empleado en la producción de una amplia variedad de manufacturas arquitectónicas, escultóricas y epigráficas, entre ellas los dos soportes catalogados. En lo que respecta a su difusión, la circulación del grueso de las manufacturas aparece circunscrita a un ámbito mucho más acotado que el observado para el mármol del Anticlinal de Estremoz, con calidades bastante inferiores a este. Según T. Nogales et alii (2009), estas variedades de grandes cristales y tonalidades cenicientas, dificultan los trabajos de labra con acabados escultóricos de nivel medio. Por su parte, J. Andreu (2011) lo define como un material muy difundido a la vez que versátil a juzgar por la heterogeneidad de su empleo. Por otro lado, A. Fusco e I. Mañas (2006) y, especialmente, Rodrigues (2007) valoran positivamente el color azulado del mármol de Trigaches como una de las razones explicativas de su intenso uso escultórico y epigráfico.

\section{Caliza de grano fino y de matriz morada con recristalizaciones calcíticas}

Los hermae realizados en este material (n. ${ }^{\text {s }} 8,13$, $14,17,18,19,20,21,28,30,34,38$ y 39) poseen una dureza destacable, cualidades adecuadas para un buen pulido. Los pilares hermaicos realizados en este material (ver figura 8) se encuentran dispersos por toda la cuenca del Guadalquivir, por lo que no podemos hablar de una zona acotada de dispersión. Un aspecto cuando menos significativo radica en que algunos de los hermae más alejados de las zonas de concentración de estos soportes se encuentran elaborados en este tipo de material.

Atendiendo a sus características macroscópicas, así como a la discriminación con respecto a otras canteras del territorio circundante, este material podría identificarse como perteneciente a la zona geológica de Alconera, ${ }^{18}$ aunque no podemos descartar la existencia de otros afloramientos de características similares ubicados dentro del territorio provincial de la Bética aún no documentados. Un ejemplo de cantera circunscrita a este territorio y que presenta semejanzas con este material sería la de Rodadero de los Lobos cercana a Arroyo de Pedroches (Córdoba), que presenta un litotipo calizo de tonalidades grisáceas, en ocasiones algo rosadas (Gutiérrez 2012).

Macroscópicamente, este conjunto de calizas estudiado presenta variedades muy heterogéneas, algunas de las cuales tienen colores muy intensos, con fondos violetas y amplias recristalizaciones blancas - como la n. ${ }^{\circ} 18$ entre otros-, otras mucho más suaves de fondos blancos y vetas lilas - como la n. ${ }^{\circ} 20-\mathrm{y}$ otras

iniciada durante el siglo I d. C., fue impulsada por la propia Pax Iulia, con el fin de proveerse de un material cercano y abundante (Mañas y Fusco 2009).

18. La localidad de Alconera se sitúa a $3 \mathrm{~km}$ de Zafra (Badajoz), muy cerca de la vía romana que unía las ciudades de Italica y Augusta Emerita. Entre estas variedades marmóreas explotadas en época romana, destaca una sobre el resto: una caliza de grano fino, de fondo morado con recristalizaciones calcíticas y pizarra, y de apariencia muy veteada (Mañas 2011b).

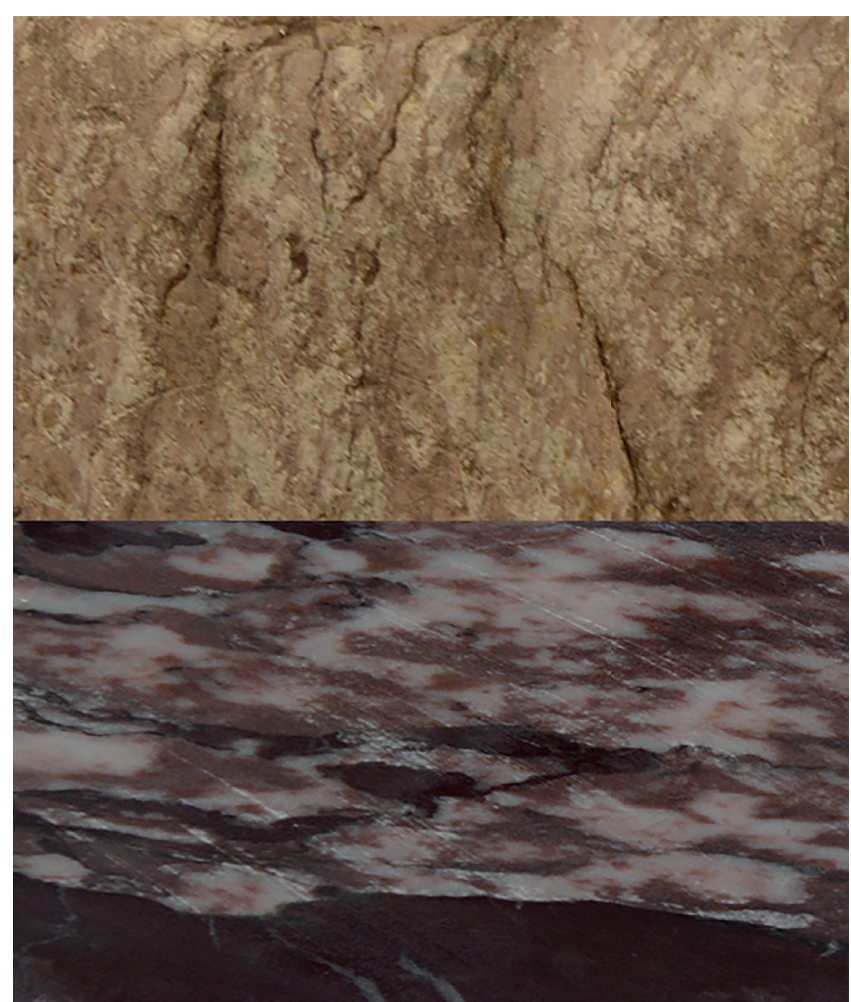

Figura 5. Diferentes variedades de la caliza de Alconera (fotografía de la autora).

de tonos rosados con vetas recristalizadas (Beltrán y Rodríguez 2010) —como la n. ${ }^{\circ} 21-$. Sin lugar a dudas, en los pilares hermaicos la variedad más utilizada es la primera, de un color púrpura intenso.

Según los estudios de I. Mañas (2009), al pie de las canteras de Alconera existiría un área en la que se trabajarían los bloques extraídos, de manera que las piezas saldrían de este lugar en un estado de semielaboración. Esta investigadora afirma, además, que "en una sola ocasión aparece documentado su uso en epigrafía"19 en una inscripción en el foro de Augusta Emerita, lo cual con este trabajo podría ampliarse, ya que, con las observaciones a visu realizadas en el ámbito de este estudio y su comparación con todos los materiales cercanos posibles, se ha podido documentar en al menos 13 ocasiones como soporte epigráfico de tipo hermaico. Aunque para poder corroborar, sin lugar a dudas, esta adscripción estaríamos a la espera de análisis arqueométricos.

\section{Caliza nodulosa de color rojo-violeta y caliza brechada de matriz rojiza con clastos de tonalidades más claras}

Los hermae realizados en este material (n. ${ }^{\text {os }} 10,11$, $12,15,22,27,35,36,37$ y 40 , rojos y n.os 24,32 y 33 , brechados) poseen una dureza superior a otras calizas de la zona y son fácilmente pulimentables. Los pilares hermaicos realizados en este material (ver figura 8) se encuentran dispersos por toda la cuenca del Guadalquivir y la zona de Antequera, por lo que

19. Sacr]um / [- - - f filius) Quir(ina tribu) / [- - - ]S / - - -. (Cf. Ramírez Sádaba 2003: 377-380). 

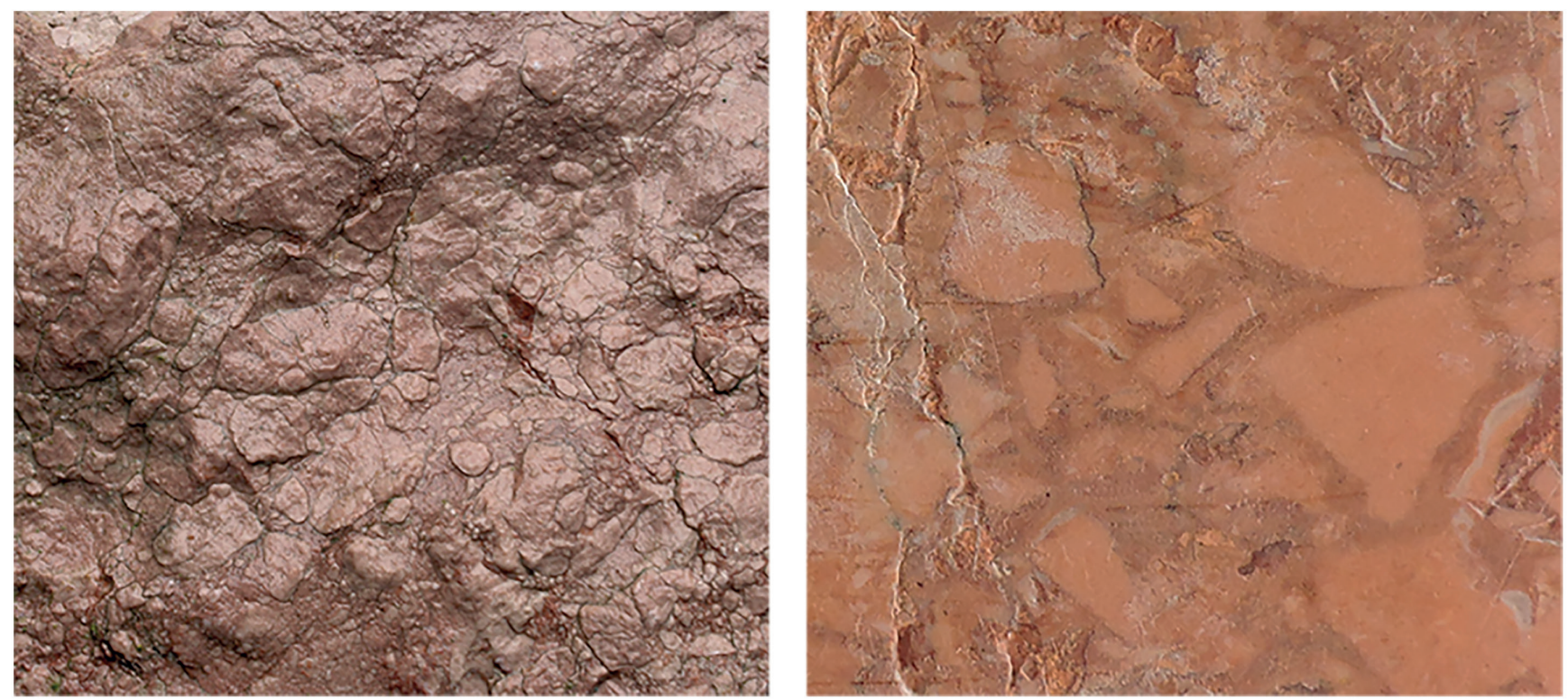

Figura 6. Diferentes variedades de la caliza del Torcal de Antequera (fotografías de la autora).

podemos hablar de una zona de dispersión acotada. Por sus características macroscópicas y el ámbito geográfico en el que aparecen los soportes hechos en este material, podrían identificarse como calizas procedentes del Torcal de Antequera, aunque no podemos descartar con seguridad otras explotaciones con materiales similares dentro de este ámbito geográfico.

Los estudios actuales permiten afirmar que, junto a las calizas del Torcal, que fueron las más importantes, se explotaron otras calizas similares en lugares cercanos, como sucede en la sierra de Cabras (Málaga), en Osuna (Sevilla), en la Sierra de los Castillejos (Málaga) o en el área de Barrida del Naranjo (Córdoba) (Gutiérrez 2012). En las ciudades romanas de este ámbito geográfico se ha documentado el empleo tanto de calizas del Torcal como de estas otras, que posiblemente complementaban la producción. Este fenómeno pudo estar relacionado con la explotación y uso de otras calizas similares, sobre todo en el surco intrabético (desde Ronda, Málaga hasta Baza, Granada) (Beltrán Fortes et alii 2012). ${ }^{20}$

20. En este sentido, $\mathbf{M}^{\mathrm{a}}$. L. Loza Azuaga y J. Beltrán Fortes (2011) identificaron un frente activo de caliza brechada rojiza en las canteras de "Piedras Lanas", de la misma manera que había hecho M. L. Segura en 1988, con la caliza rojiza usada como soporte epigráfico durante los siglos I y III d. C., considerándola perteneciente a las canteras de "Los Lanchares". La explotación antigua de mayor tamaño de esta tipología está situada a unos $4 \mathrm{~km}$ de la ciudad de Antequera, formando una cordillera caliza, parte del sistema penibético. La existencia de canteras contemporáneas en esta zona ha borrado casi todos los restos de explotaciones antiguas y posibles manufacturas abandonadas. Aunque se pueden diferenciar varios tipos litológicos, el que mayormente nos interesa es la caliza fosilífera gris-rojiza, explotada desde la antigüedad, que hemos creído reconocer en algunas de las piezas (Álvarez et alii 2009). Los trabajos de Beltrán, Azuaga, Rodríguez, Ontiveros y Taylor en estos sectores apuntan la existencia de un empleo regionalizado de las variedades mencionadas, donde las canteras del Torcal actuarían como material de mayor calidad, probablemente
En época romana, la circulación de la caliza del Torcal supera los límites regionales, difundiéndose a todo el territorio de la provincia. El uso de este material se documenta principalmente en placas y soportes epigráficos, como constata el volumen de hermae realizados en él.

\section{Caliza policroma de grano fino}

Solo se han documentado un herma realizado en este material (n. ${ }^{\circ} 31$ ), además de otro (n. ${ }^{\circ}$ 26) que, a falta de una autopsia in situ, ha sido argumentado como perteneciente a esta tipología en base a la descripción ofrecida por Portillo, Rodríguez y Stylow en su trabajo de 1985, definido como una caliza ocre con moteados en varios colores, lo que unido al lugar

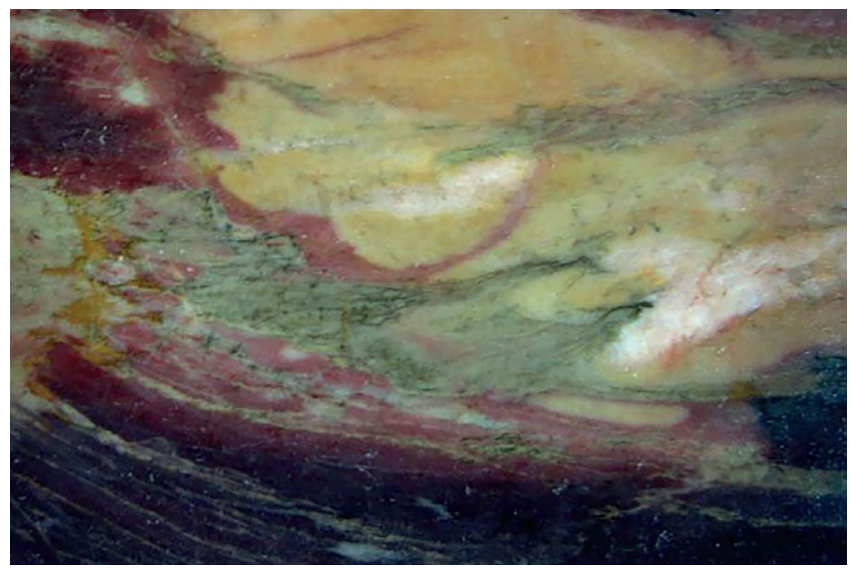

Figura 7. Caliza de Peñaflor (fotografía realizada por Begoña Soler Huertas).

asociadas a la presencia de talleres especializados vinculados a la cantera (Beltrán Fortes et alii 2012). 
Laura Galán Palomares, Los soportes hermaicos en Hispania: estudio sobre la funcionalidad y dispersión geográfica de los hermae..

\begin{tabular}{|c|c|c|c|c|c|c|c|}
\hline $\begin{array}{l}\text { Identificación tipológica } \\
\text { del material (a visu) }\end{array}$ & Soporte hermaico $\left(\mathrm{n}^{0}\right)$ & Ámbito geográfico & Alto (cm) & Ancho $(\mathrm{cm})$ & Fondo (cm) & Encajes laterales (cm) & Encaje Superior \\
\hline \multirow[b]{2}{*}{ Märmol de Trigaches } & 1 & \multirow[b]{2}{*}{ Pax Iulia } & (49) & 30 & 22 & Izdo.: - $\mathrm{x}-\mathrm{x}$-- Dcho.: - $\mathrm{x}-\mathrm{x}$-- & Rebaje con espiga centrada en él \\
\hline & 2 & & (62) & $30-23,3$ & $19,5-17$ & $\begin{array}{l}\text { Izdo: } 7,7 \times 8 \times 2,7 \\
\text { Dcho: } 7,7 \times 8 \times 2,7\end{array}$ & Rebaje de $2 \mathrm{~cm}$ con espiga centrada en él \\
\hline \multirow{5}{*}{$\begin{array}{l}\text { Mármol del anticlinal de } \\
\text { Estremoz }\end{array}$} & 3 & \multirow{5}{*}{ Augusta Emerita } & (48) & $23-20,5$ & 12 & Izdo.: Perno Dcho.: Perno & Encaje de sección semicircular cóncavo \\
\hline & 4 & & (48) & $20-16$ & 13 & Izdo.: Perno Dcho.: Perno & Encaje de sección semicircular cóncavo \\
\hline & 5 & & (59) & 25,5 & 20 & Izdo.: Perno Dcho.: Perno & Encaje de sección semicircular cóncavo \\
\hline & 6 & & $(60)$ & $26,5-23$ & 20,5 & Izdo.: $10 \times 5 \quad$ Dcho.: $10 \times 5$ & Encaje de sección semicircular cóncavo \\
\hline & 7 & & (62) & 30 & 18 & $\begin{array}{l}\text { Izdo.: Desconocido } \\
\text { Dcho.: Desconocido }\end{array}$ & Encaje de sección semicircular cóncavo \\
\hline \multirow{13}{*}{$\begin{array}{c}\text { Posible caliza de } \\
\text { Alconera / Caliza de } \\
\text { Rodadero de los Lobos / } \\
\text { Otras canteras } \\
\text { desconocidas }\end{array}$} & 8 & \multirow{3}{*}{ Obulco } & (95) & $22,5-23,5$ & 19,5 & $\begin{array}{l}\text { Izdo.: } 10,7 \times 5 \times 2,3 \\
\text { Dcho.: } 10,5 \times 6 \times \text {-- }\end{array}$ & $\begin{array}{l}\text { Rebaje de } 2,5 \mathrm{~cm}, \emptyset=20 \mathrm{~cm} \text {, espiga a } 5 \mathrm{~cm} \text { de la } \\
\text { cara frontal }\end{array}$ \\
\hline & 13 & & (112) & $24,5-18$ & 14,5 & $\begin{array}{l}\text { Izdo.: } 10 \times 5 \times 2,5 \\
\text { Dcho: } 10 \times 5 \times 2,5\end{array}$ & Rebaje semicircular con espiga atrasada \\
\hline & 14 & & $(43,5)$ & $29-27,5$ & 18 & $\begin{array}{l}\text { Izdo.: Perno } \\
\text { Dcho.: Perno }\end{array}$ & $\begin{array}{l}\text { Rebaje de } 4,5 \mathrm{~cm}, \emptyset=17 \mathrm{~cm} \text {, espiga a } 12 \mathrm{~cm} \mathrm{de} \\
\text { la cara frontal }\end{array}$ \\
\hline & 17 & \multirow{5}{*}{ Corduba } & $(38,5)$ & $27-25,8$ & 16 & $\begin{array}{l}\text { Izdo.: } 8 \times 5,5 \times 3 \\
\text { Dcho.: } 8 \times 5,5 \times 3\end{array}$ & $\begin{array}{l}\text { Dos orificios de } 2 \mathrm{~cm} \text { de } ø \text { con pasadores de } \\
\text { plomo }\end{array}$ \\
\hline & 18 & & (102) & $26-22$ & 14 & $\begin{array}{l}\text { Izdo.: } 10 \times 4 \times 1,5 \\
\text { Dcho.: } 10 \times 4 \times 1\end{array}$ & $\begin{array}{l}\text { Rebaje de } 2 \mathrm{~cm}, \varnothing=23 \mathrm{~cm} \text {, espiga a } 7 \mathrm{~cm} \text { de la } \\
\text { cara frontal }\end{array}$ \\
\hline & 19 & & (68) & $22,5-20,5$ & 14 & $\begin{array}{l}\text { Izdo.: } 7,5 \times 4 \times 2,5 \\
\text { Dcho.: } 8 \times 5 \times 2 \times 2\end{array}$ & $\begin{array}{l}\text { Rebaje de } 2 \mathrm{~cm}, \emptyset=18 \mathrm{~cm} \text {, espiga a } 8 \mathrm{~cm} \mathrm{de} \mathrm{la} \\
\text { cara frontal }\end{array}$ \\
\hline & 20 & & (68) & $25-22$ & 12 & $\begin{array}{l}\text { Izdo:: } 9 \times 4,2 \times 1,5 \\
\text { Dcho.: } 7,5 \times 4,5 \times 1\end{array}$ & Rebaje circular de 2-1,5 cm, con espiga \\
\hline & 21 & & $(31,5)$ & 23,5 & 14 & $\begin{array}{l}\text { Izdo.: }--\mathrm{x}-\mathrm{x}-- \\
\text { Dcho:: } 9 \times 3 \times 1,5\end{array}$ & Rebaje circular de $0,5 \mathrm{~cm}$, con espiga \\
\hline & 28 & \multirow{3}{*}{ Astigi } & (115) & $25-20$ & 12,5 & $\begin{array}{l}\text { Izdo.: } 8 \times 4,5 \times 1,8 \\
\text { Dcho.: } 8,8 \times 6,3 \times 2\end{array}$ & Rebaje circular de $2 \mathrm{~cm}$, con espiga \\
\hline & 30 & & $(86-73)$ & $25,5-23,5$ & $20,5-16,5$ & $\begin{array}{l}\text { Izdo.: }(5) \text { x 4,5 x 2,5 } \\
\text { Dcho.: -- x -- x -- }\end{array}$ & $\begin{array}{l}\text { Rebaje de } 3 \mathrm{~cm}, \emptyset=19,5 \mathrm{~cm} \text {, con espiga a } 10 \mathrm{~cm} \\
\text { de la cara frontal }\end{array}$ \\
\hline & 34 & & $(81)$ & 22 & 14 & Izdo:: Perno $\quad$ Dcho.: Perno & Rebaje circular con espiga atrasada \\
\hline & 38 & \multirow{2}{*}{ Dispersas } & (41) & 23 & 12 & Izdo: $8 \times 5 \times$-- Dcho.: $8 \times 5 \times--$ & Rebaje con $\varnothing=18 \mathrm{~cm}$ y sppiga centrada \\
\hline & 39 & & (53) & $24-20$ & 10,5 & Izdo.: $--\mathrm{x}-\mathrm{x}--$ Dcho.: $-\mathrm{x}--\mathrm{x}-$ & Desconocido \\
\hline
\end{tabular}

\begin{tabular}{|c|c|c|c|c|c|c|c|}
\hline $\begin{array}{c}\text { Identificación tipológica } \\
\text { del material (a visu) }\end{array}$ & Soporte hermaico $\left(\mathbf{n}^{\circ}\right)$ & Ámbito geográfico & Alto (cm) & Ancho (cm) & Fondo (cm) & Encajes later ales (cm) & Encaje Superior \\
\hline \multirow{10}{*}{$\begin{array}{l}\text { Posible caliza del Torcal } \\
\text { de Antequera / Sierra de } \\
\text { Cabras / Sierrad de los } \\
\text { Castillejos (Málaga) } \\
\text { Osuna (Sevilla) } \\
\text { Barrida del Naranjo } \\
\text { (Córdoba) } \\
\text { Otras canteras del surco } \\
\text { intrabético }\end{array}$} & 10 & \multirow{4}{*}{ Obulco } & (56) & $28-25,5$ & $16-15,3$ & \begin{tabular}{|l} 
Izdo.: $-\mathrm{x}--\mathrm{x}--$ \\
Dcho:: $8,7 \times 5,2 \times 2,8$
\end{tabular} & $\begin{array}{l}\text { Rebaje de } 4 \mathrm{~cm} \text { de profundidad, } \boldsymbol{ø}=20 \mathrm{~cm}, \\
\text { espiga a } 7 \mathrm{~cm} \text { de la cara frontal }\end{array}$ \\
\hline & 11 & & (62) & $28,5-25,5$ & $17-15$ & \begin{tabular}{|l} 
Izdo.: $9,5 \times 5,7 \times 2,5$ \\
Dcho.: $9 \times 6 \times--$
\end{tabular} & 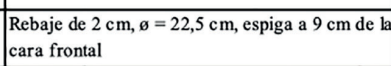 \\
\hline & 12 & & 144 & $28-20$ & 15 & $\begin{array}{l}\text { Izdo: } 9 \times 3,5 \times 1,3 \\
\text { Dcho:: } 9 \times 3,5 \times 1,3\end{array}$ & Rebaje de $2 \mathrm{~cm}, \varnothing=20 \mathrm{~cm}$, con espiga centrada \\
\hline & 15 & & -- & $-\cdot$ & -- & Izdo.:-- x--x-- Dcho.:-- x-- x-- & Desconocido \\
\hline & 22 & Corduba & $(77,5)$ & $23,5-20,8$ & $13,5-13$ & $\begin{array}{l}\text { Izdo: } 9 \times \cdots \times 1,8 \\
\text { Dcho: } 8,8 \times 6,3 \times 2\end{array}$ & Rebaje circular de $0,5 \mathrm{~cm}$, con espiga \\
\hline & 27 & Astigi & (52) & $25,5-24$ & 13 & 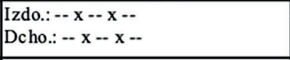 & Rebaje circular con espiga \\
\hline & 35 & \multirow{3}{*}{ Malaca } & (78) & $26,5-23$ & $17-15$ & \begin{tabular}{|l|} 
Izdo.: $8 \times 4 \times--$ \\
Dcho.: $8 \times 4 \times-$ \\
\end{tabular} & $\begin{array}{l}\text { Rebaje circular, con espiga que presenta un } \\
\text { orificio de sec ción cuadrangular }\end{array}$ \\
\hline & 36 & & $(86)$ & $25-23,5$ & 16 & $\begin{array}{l}\text { Izdo.: } 8,5 \times 5,2 \times 1,4 \\
\text { Dcho:: } 8,5 \times 5,7 \times 1,4\end{array}$ & Rebaje de $1 \mathrm{~cm}, \varnothing=23 \mathrm{~cm}$ y espiga centrada \\
\hline & 37 & & $(45)$ & (14) & 19 & $\begin{array}{l}\text { Izdo.: } 10 \times 5 \times 2,5 \\
\text { Dcho.: } 10 \times 5 \times 2,5\end{array}$ & Desconocido \\
\hline & 40 & Dispersa & (32) & 26 & $(10,5-9)$ & \begin{tabular}{|l|} 
Izdo.: $--\mathrm{x}-\mathrm{x}--$ \\
Dcho.:-- $\mathrm{x}-\mathrm{x}--$
\end{tabular} & Desconocido \\
\hline \multirow{3}{*}{$\begin{array}{l}\text { Posible caliza del Torcal } \\
\text { brechada }\end{array}$} & 24 & Corduba & $-\cdot$ & $\cdot-$ & -- & 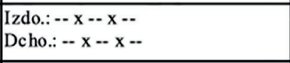 & Desconocido \\
\hline & 32 & \multirow{2}{*}{ Astigi } & $(64,4)$ & $23-21,1$ & $11,8-11,2$ & $\begin{array}{l}\text { Izdo.: } 7 \times 3,5 \times 0,7 \\
\text { Dcho:: } 6,5 \times 4 \times 0,6\end{array}$ & $\begin{array}{l}\text { Rebaje de } 1,5 \mathrm{~cm}, 6=17,5 \mathrm{~cm} \text {, con espiga que } \\
\text { presenta un orificio de sección cuadrangular de } \\
4,1 \times 1,8 \times 3,2 \mathrm{~cm}\end{array}$ \\
\hline & 33 & & $(27,5)+(28,2)$ & $20,6-18,7$ & 18,3 & \begin{tabular}{|l} 
Izdo.: $7,2 \times 4,2 \times 0,4$ \\
Dcho: $7,2 \times 4,5 \times 0,3$
\end{tabular} & $\begin{array}{l}\text { Rebaje de } 1,5 \mathrm{~cm}, \varnothing=18 \mathrm{~cm} \text {, con espiga que } \\
\text { presenta un orificio de sección cuadrangular de } \\
3,5 \times 3,1 \times 4 \mathrm{~cm}\end{array}$ \\
\hline \multirow[b]{2}{*}{ Caliza de Peñaflor } & 26 & \multirow[b]{2}{*}{ Astigi } & (66) & $27,5-25$ & 16,5 & $\begin{array}{l}\text { Izdo.:- }-x-x-x- \\
\text { Dcho::--x-x-- }\end{array}$ & Rebaje circular con espiga \\
\hline & 31 & & $(125-121)$ & $28,8-17,5$ & 14,5 & \begin{tabular}{|l|} 
Izdo: $9,2 \times 3,9 \times 0,7$ \\
Dcho.: $9,2 \times 3,9 \times 0,7$
\end{tabular} & $\begin{array}{l}\text { Rebaje de } 1,5 \mathrm{~cm}, \emptyset=12,3 \mathrm{~cm} \text {, con espiga que } \\
\text { presenta un orificio de sección cuadrangular de } \\
4,3 \times 2 \times 4,1 \mathrm{~cm}\end{array}$ \\
\hline \multirow{5}{*}{ Desconocido } & 9 & Obulco & -- & -- & -- & Izdo.:-- x-- x-- Dcho.:-- x-- x-- & Desconocido \\
\hline & 16 & \multirow{3}{*}{ Corduba } & $-\cdot$ & 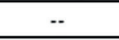 & - & Izdo.:-- x--x-- Dcho.:--x--x-- & Desconocido \\
\hline & 23 & & -- & -- & - & 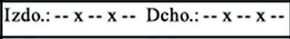 & Desconocido \\
\hline & 25 & & -- & -- & - & Izdo.:- $-x \cdots \mathrm{x} \cdots$ Dcho.:- $-\mathrm{x} \cdots \mathrm{x}--$ & Desconocido \\
\hline & 29 & Astigi & -- & -- & -- & Izdo.:-- x--x-- Dcho.:-- x-- $\mathrm{x}--$ & Desconocido \\
\hline
\end{tabular}

Figura 8 (8.1 y 8.2). Cualidades físicas de los soportes hermaicos hispanos. 


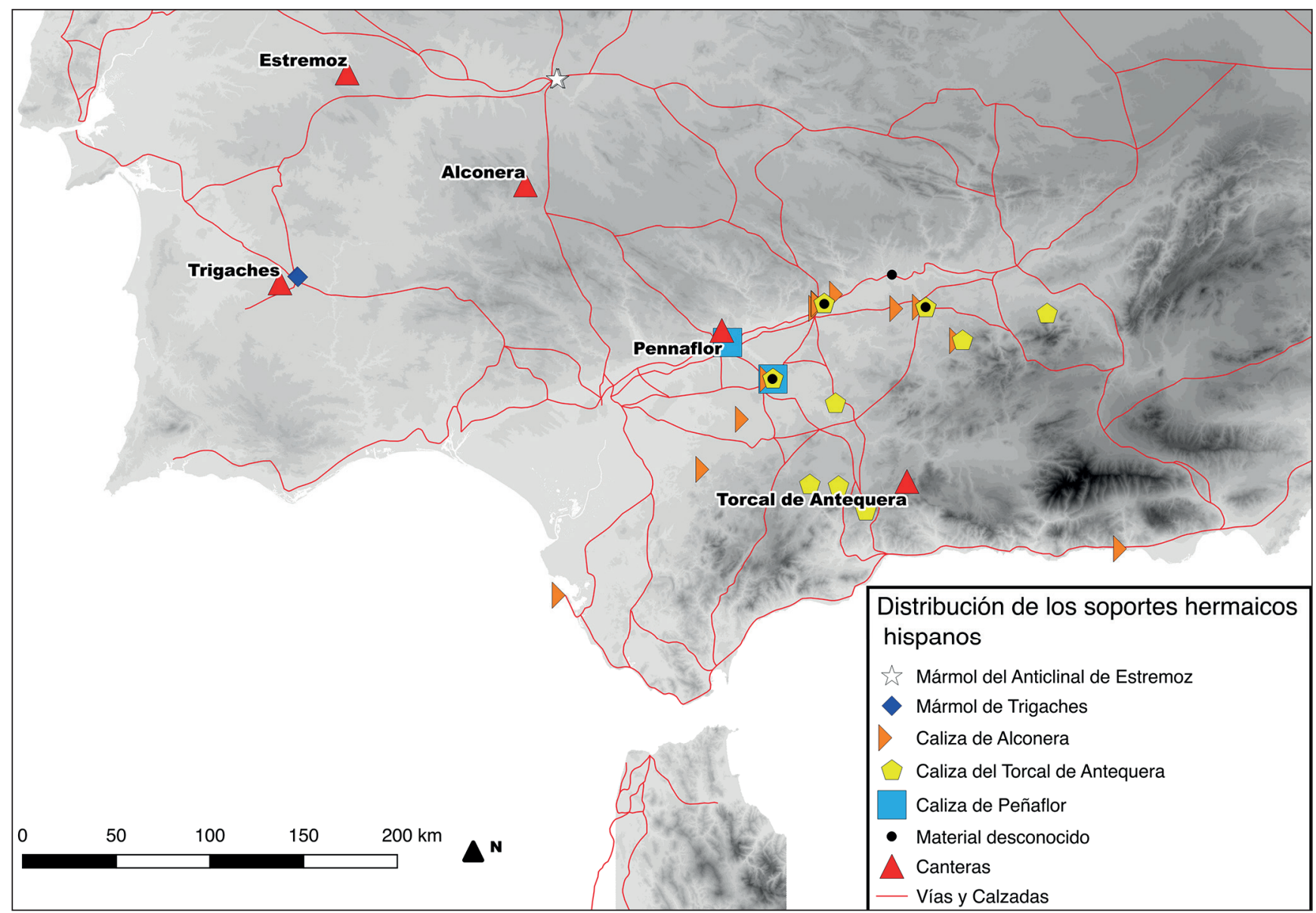

Figura 9. Mapa de distribución de los soportes hermaicos hispanos clasificados según la posible procedencia de su material. ${ }^{21}$

de su hallazgo — la localidad de Peñaflor, donde se sitúan las canteras- podría abalar dicha procedencia. El grano fino de esta caliza permite un suave pulido, así como confiere buena resistencia. Por su coloración y sus características macroscópicas podemos identificar este material como caliza de Peñaflor. Los pilares hermaicos realizados en este material (ver figura $8, \mathrm{n}^{\text {os }} 26 \mathrm{y} 31$ ) se han documentado en el ámbito geográfico cercano al entorno de Peñaflor y Écija - donde durante las excavaciones llevadas a cabo en Celti (Peñaflor) apareció este litotipo de forma frecuente, lo cual plantea una ubicación cercana de las canteras, aunque todavía no están localizadas de manera exacta - por lo que podríamos estar ante una difusión limitada. No obstante, y de ser correcta su identificación, estaríamos ante los primeros soportes epigráficos elaborados en este material. ${ }^{22}$

21. Véase "Pennaflor" como Peñaflor.

22. La caliza de Peñaflor es un material con un grado de cristalización muy elevado que le proporciona dureza y compactación; posee una amplísima variedad cromática (Beltrán y Rodríguez 2010), con tonalidades que van desde verde hasta tonos rojos, ocres, amarillos y anaranjados con distintos matices violáceos. Quizás por este rico cromatismo fue utilizado en varios edificios públicos de la Bética (Portillo 2016). Algunos de los ejemplos de empleo más significativos los encontramos en la praecinctio inferior de la cavea del teatro romano de

\section{Distribución geográfica de los litotipos}

El análisis macroscópico de los diferentes litotipos empleados en los soportes hermaicos catalogados determina el empleo de materiales de procedencia preferentemente local, caracterizados por un marcado carácter ornamental y dotados de ciertas cualidades cromáticas. El elenco de materiales identificados, de acuerdo con las áreas geográficas diferenciadas, parece confirmar la existencia de cierta preferencia por el aprovisionamiento de variedades muy concretas protagonizadas por las variedades de intensa coloración rojiza, quizás procedentes del Torcal de Antequera / surco intrabético y las diferenciadas como tipo Alconera / Rodadero de los Lobos.

Italica o en una gran losa situada en el umbral de ingreso a la iglesia de Santa María en Écija. Las dimensiones alcanzadas por algunas de estas piezas sugieren la presencia de frentes de cantera de cierta entidad con una producción diversificada. P. Pensabene, refiriéndose a ella como "breccia di Peñaflor", la define como uno de los mármoles hispánicos de color más empleados en ciudades relevantes de la Baetica como Carmo o Astigi (Pensabene 2014). En cuanto a su cronología, su explotación parece iniciarse en época augustea, manteniéndose activa hasta prácticamente época adrianea (Rodríguez 2009). 
Esta tendencia permitiría contextualizar la circulación de estos materiales dentro de un mercado de carácter regional, con un radio de acción de hasta más de $200 \mathrm{~km}$ para determinados materiales. Por otro lado, pondría de manifiesto la existencia de un mercado paralelo al de los lujosos marmora de importación, integrado por diferentes variedades definidas por una dispersión acotada, pero que en algunos casos pudieron ser comercializadas a nivel provincial como consecuencia de su llamativa coloración y grado de prestigio asociado.

Centrándonos en el análisis material de los soportes documentados, se observa cierta predilección por determinado tipo de variedades, aunque sus características físicas fuesen similares a otros materiales beneficiados en canteras locales. Esto pudo deberse al nivel de prestigio alcanzado por algunos litotipos, pero también a la circulación de manufacturas muy concretas producidas por talleres especializados en la labra de una variedad concreta de material.

En la provincia Baetica los soportes hermaicos aparecen labrados, en general, sobre calizas de tonos rojizos, púrpuras y rosados; mientras que en la Lusitania se recurre al empleo de mármoles blancos o blancos-grisáceos. De todo ello se deduce la presencia de producciones condicionadas per la tipología de rocas explotada en la zona, así como por la existencia de mercados nutridos con la producción de determinados talleres.

Por otro lado, atendiendo a la datación de los soportes hermaicos, establecida en base a sus características paleográficas, ante la ausencia de contexto arqueológico para muchos de ellos, se observan ciertas similitudes temporales entre las piezas labradas en un mismo material, obteniendo la siguiente sistematización:

- El uso del mármol de Trigaches para la producción de los ejemplares de Pax Iulia podría situarse dentro de una cronología aproximada de mediados del siglo i d. C.

- Por otro lado, la utilización del mármol del Anticlinal de Estremoz para la ejecución de los soportes hermaicos emeritenses, estaría fechada a partir del primer tercio del siglo I, sin superar el primer cuarto del siglo II $d$. C.

- En el caso de los soportes realizados en posible caliza de Alconera / caliza de Rodadero de los Lobos difundidos por el valle del Guadalquivir, el uso de este material podría fecharse a partir de la segunda mitad del siglo i hasta prácticamente finales del siglo I y principios del II d. C.

- La caliza de la zona del Torcal de Antequera / surco intrabético fue usada para la realización de soportes hermaicos desde el último cuarto del siglo I d. C. hasta finales del siglo II d. C.

- Por último, la caliza de Peñaflor, en base al soporte n. $^{\circ} 31$, que sin dudas podemos atribuir a este material, parece que fue usada como soporte de hermae a partir del siglo II d. C. No obstante, de confirmarse la identificación propuesta para el soporte ${ }^{\circ}{ }^{\circ} 26$, su empleo estaría atestiguado ya a inicios del siglo I d. C.

\section{En búsqueda de los talleres: características físicas y epigráficas}

Ahondando en el estudio de los formatos y estilos de los soportes y poniéndolo en relación con la tipología del material empleado en la producción de los soportes, hemos querido abordar desde las características morfológicas y paleográficas el proceso de producción y el grado de formación de los talleres que los elaboraron.

\section{Técnicas de talla y morfología de los encajes}

Tal y como avanzábamos en las delimitaciones espacio-temporales y de acuerdo con el mapa preliminar trazado para la difusión de este tipo de soportes, podemos diferenciar tres áreas muy concretas: por un lado, la gran zona geográfica de la cuenca del Guadalquivir y, por otro, las dos ciudades de la Lusitania, Pax Iulia y Augusta Emerita. En las tres zonas de difusión, los pilares hermaicos comparten una misma tendencia hacia la forma troncopiramidal, así como la presencia de un encaje superior y dos elementos de sujeción -en forma de encaje o solamente con pernos metálicos-, uno a cada lado, para la fijación de los muñones laterales. Por otro lado, todos ellos debieron presentar un encaje en la zona inferior destinado a la fijación sobre un pedestal que haría de base estable, tal y como se observa en los dibujos conservados para los n.os 16 y 24, hoy desaparecidos, y en la fotografía del n. ${ }^{\circ} 13$, actualmente conservado en una colección privada.

\section{Dimensiones y técnicas de talla (ver figura 8)}

El análisis global de las dimensiones establecidas para el conjunto de soportes analizado constituye un aspecto fundamental para la correcta definición de las manufacturas y la posible identificación de producciones elaboradas por un mismo taller. De la misma forma, la sistematización de acuerdo con el tipo de roca empleada es esencial en la identificación de producciones concretas.

Mientras que los soportes procedentes de Pax Iulia presentan unas dimensiones estables, fijadas entre los $30 \mathrm{~cm}$ y $20 \mathrm{~cm}$ de fondo, en Augusta Emerita se diferencian dos grupos: en el primero, la anchura se establece en $26 \mathrm{~cm}$ y el fondo en $20 \mathrm{~cm}$; en el segundo, la anchura varía bastante entre la parte superior y la inferior, siendo de media de unos $20 \mathrm{~cm}$, mientras que la anchura del fondo se fija en $12 \mathrm{~cm}$. Fuera de ambos conjuntos estaría el soporte n. ${ }^{\circ} 7$ que con una anchura de $30 \mathrm{~cm}$ y fondo de $18 \mathrm{~cm}$ presenta dimensiones similares a las establecidas para la zona de Pax Iulia, diferencia que podría estar relacionada con la funcionalidad desempeñada por el elemento, constituyendo hasta la fecha el único soporte hermaico de carácter funerario documentado en Hispania.

En lo que respecta al valle del Guadalquivir, los soportes hermaicos realizados en caliza del Torcal de Antequera presentan unas dimensiones, más o 
menos homogéneas, establecidas entre los $25 \mathrm{~cm}$ de anchura y los $15 \mathrm{~cm}$ de profundidad. Por su parte, los ejemplares procedentes de Porcuna presentan una anchura de $28 \mathrm{~cm}$, algo superior que la establecida para el resto del conjunto. También los soportes labrados en caliza brechada del Torcal observan variaciones, cuyas dimensiones oscilan entre los 23$18 \mathrm{~cm}$ de anchura y los $18-11 \mathrm{~cm}$ de fondo. Tales diferencias pudieron responder a condicionamientos de carácter técnico, derivados de la calidad de la veta beneficiada, e incluso a su elaboración en distintos momentos cronológicos. Otra posibilidad es que estemos, en el caso de Obulco, ante un taller propio en el que se utilizaba un material cercano con unas características litológicas muy similares a las de la zona de Antequera.

Respecto a los pilares elaborados en caliza tipo Alconera, su anchura oscila entre los $24-20 \mathrm{~cm}$ y los $18-14 \mathrm{~cm}$ de profundidad, dimensiones similares a las documentadas en los hermae labrados en caliza de Peñaflor, los cuales suelen ser algo más anchos, $28 \mathrm{~cm}$.

Atendiendo al trabajo de sus cuatro caras, observamos cómo la frontal y las laterales están siempre pulimentadas, mientras que en más del $90 \%$ de los casos la cara trasera se encuentra solamente desbastada o con un alisado basto; esto tiene sentido, pues estos soportes normalmente iban apoyados contra la pared externa del tablinum.

\section{Morfología de los encajes superiores y laterales (ver figura 8)}

En este análisis se ha mantenido el estudio diferenciado de las tres áreas geográficas comentadas dadas las variaciones observadas en la morfología de los anclajes para cada una de ellas.

En Pax Iulia y en el valle del río Betis los encajes superiores constan de un rebaje de tendencia semicircular de unos $2 \mathrm{~cm}$ de profundidad, dotados de espiga cónica centrada y sobresaliente unos $10 \mathrm{~cm}$. Mientras que en Augusta Emerita el encaje para los bustos responde a un vaciado, siguiendo una sección de tendencia circular, lo que le confiere una forma cóncava. Cabe mencionar separadamente el grupo de Astigi, en los que se puede observar un encaje de pequeñas dimensiones y sección cuadrangular en la parte superior de la espiga, que proporcionaría una mayor sujeción para los bustos. Al margen de esta diferencia, la morfología de los encajes analizados para el conjunto de hermae documentados en la $\mathrm{Ba}$ etica se caracteriza por su homogeneidad, definidos por la presencia de un rebaje circular con una espiga centrada donde encajar el busto.

Centrándonos ahora en los encajes laterales, se diferencian los soportes de Pax Iulia y Augusta Emerita por un lado y los del área del Guadalquivir por otro, observando ciertas particularidades en el conjunto de Écija.

En Pax Iulia, solo se conocen las dimensiones de los encajes laterales de uno de los soportes hermaicos, caracterizado por su sección rectangular, casi cuadrada, algo más anchos que largos. En Augusta Emerita, salvo en el caso del soporte n. ${ }^{\circ}$ 6, que posee escotaduras de sección rectangular a ambos lados, ninguno de los soportes hermaicos presenta rebajes laterales, poseyendo solamente un perno metálico a cada lado para sujetar los muñones. Respecto al valle del Guadalquivir, todos los soportes hermaicos presentan rebajes laterales de sección rectangular a sendos lados.

Atendiendo a sus dimensiones, mientras que los grupos de Córdoba y Porcuna presentan dimensiones similares, de $10-9 \mathrm{~cm}$ de alto por unos $5 \mathrm{~cm}$ de ancho y una profundidad que varía entre los 2,5 y $1,5 \mathrm{~cm}$, en Écija los encajes laterales son algo más pequeños, de aproximadamente $7 \mathrm{~cm} \times 4 \mathrm{~cm}$ y menos profundos.

En lo que respecta al material empleado en la labra de los muñones se ha podido documentar únicamente en el soporte n. ${ }^{\circ} 11$ procedente de Porcuna, que parece elaborado en el mismo material que el soporte. Se ha hipotetizado que pudieran ser de madera o de piedra - del mismo material o distinto al soporte-, pero la ausencia de más datos no nos permite avanzar conclusiones. Este muñón, en ocasiones iría fijado con algún tipo de adhesivo, mientras que, en otras, estaría anclado al soporte mediante pernos.

De todo ello se deduce que el conjunto de pilares hermaicos analizado presenta unas dimensiones estandarizadas de un 1,5\% más de ancho que de fondo. En el área de Pax Iulia, donde se documentan algunos de los ejemplares más tempranos, vemos cómo
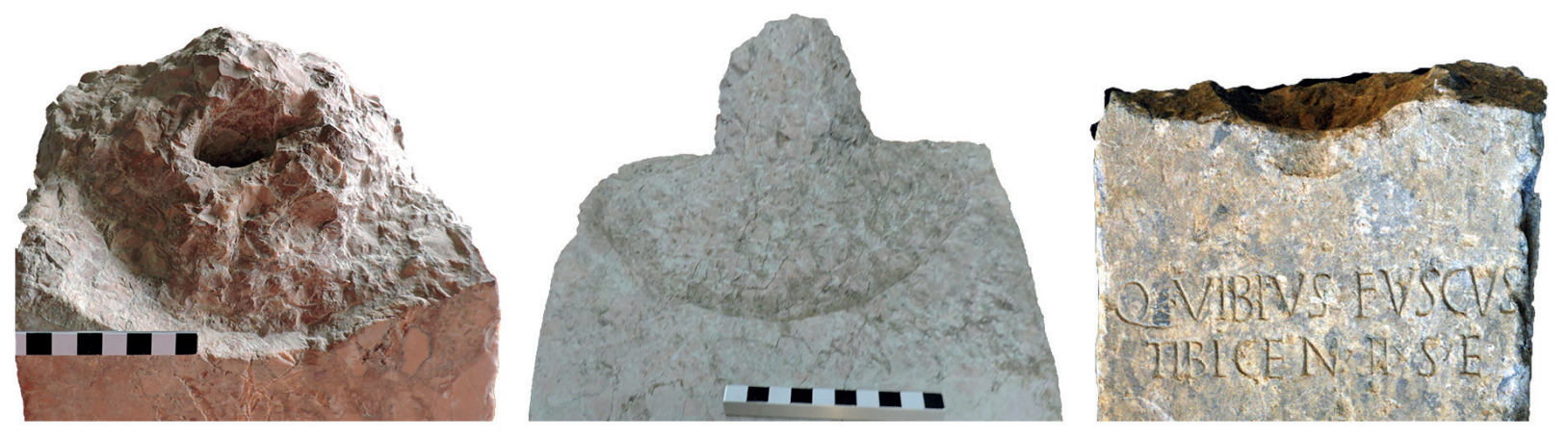

Figura 10. Ejemplos de encajes superiores de los soportes hermaicos $n .^{\circ s} 36,32$ y 7 , según el catálogo de la autora. 


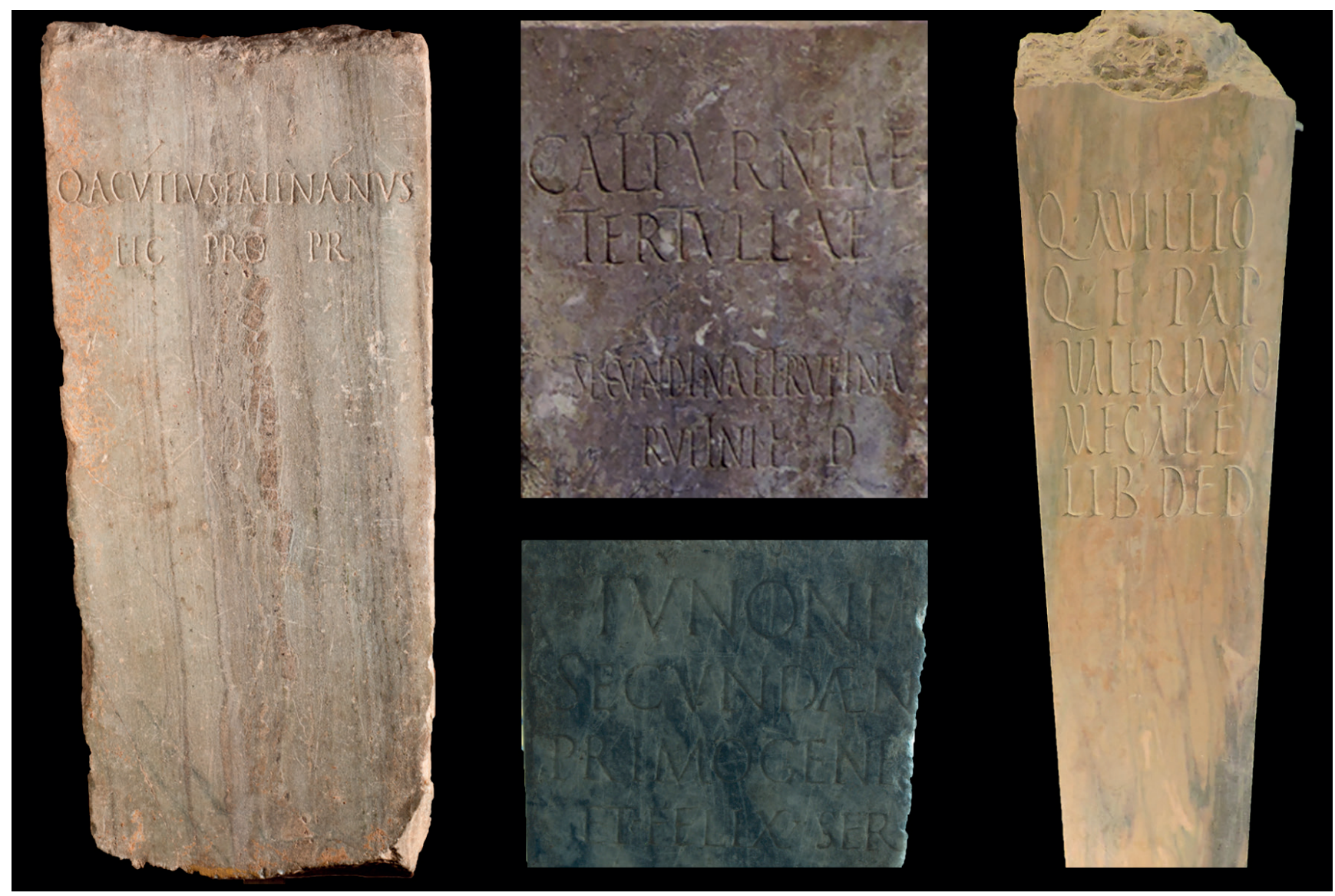

Figura 11. Cuerpo epigráfico de los soportes hermaicos $n^{\circ{ }^{o s}} 6,18,2$ y 31 según el catálogo de la autora.

la anchura - aproximadamente $30 \mathrm{~cm}$ - es algo mayor que en el resto de zonas -entre 26 y $24 \mathrm{~cm}$ - Los casos de la caliza nodulosa de Porcuna y los de la caliza brechada tipo Torcal distan, en cierto modo, de estas generalidades.

Poniendo en relación los análisis de los encajes superiores y los rebajes laterales, podemos observar cómo el grupo de Augusta Emerita aparece muy bien diferenciado sobre el resto, siendo el único con encaje superior excavado y con la presencia generalizada solo de pernos metálicos para la sujeción de los muñones. Por otra parte, estaría el grupo de Pax Iulia, con unas dimensiones diferenciadas de los ejemplos de la Baetica. Y, por último, cabe hablar del grupo del valle del Guadalquivir, dentro del cual cabría diferenciar el ámbito geográfico de Astigi, en el cual los encajes superiores y laterales presentan ligeras diferencias respecto al resto, que hacen que lo debamos considerar como un grupo aparte.

Teniendo en cuenta todo lo anterior podemos concluir, por un lado, que los bloques troncopiramidales saldrían ya esbozados de la cantera y, por otro, que existía una serie de talleres en donde se realizarían los encajes superiores y laterales. Con esto, podríamos diferenciar, al menos, cuatro talleres, uno en Augusta Emerita, otro en Pax Iulia y dos en la Baetica, uno en el ámbito geográfico de Corduba-Obulco y otro en la zona de influencia de Astigi.

\section{Características epigráficas: paleografía y fórmulas habituales (ver figura 12)}

Debido a la característica inscripción en la cara frontal de todos los soportes hermaicos hispanos, es importante realizar un estudio exhaustivo sobre la paleografía y el contenido de las inscripciones - formulario- para poder ampliar la información sobre la producción y los talleres de estos pilares.

Centrándonos en el tipo de letra y, en concreto, en la forma de la letra, puede ser del tipo más recto, propio del módulo de la capital cuadrada, o mantener la tendencia más curvilínea de la actuaria — si observamos la siguiente tabla podemos apuntar que la elección no está condicionada por el material utilizado- Del mismo modo, a partir de la tipología de encajes superiores, vemos como tampoco estaría asociado exclusivamente a un tipo de encaje en concreto. Esto nos lleva a pensar que las inscripciones fueron probablemente realizadas en un taller epigráfico una vez terminado el soporte, posiblemente en el mismo momento en que se encastrase el busto.

\section{La paleografía y la ordinatio}

El número de inscripciones con paleografía que responde a los modos de la capital cuadrada representa el 50\% del total, lo que se encuadra dentro de la coyuntura cronológica en la que surgen los primeros 
soportes hermaicos hispanos, tras el asentamiento de los soldados retirados en las ciudades que nos incumben en el siglo I d. C. Este grupo representa el inicio de la creación de estos soportes en Hispania, mientras que los soportes cuyos textos reflejan una paleografía de tendencia actuaria están situados a finales del siglo i d. C. y los que ya emplean la forma actuaria se sitúan ya en el siglo II d. C.

En lo que respecta a sus características más formales, vemos cómo por norma general los textos de las inscripciones hermaicas hispanas no aparecen delimitados, a excepción de dos de los casos: n. ${ }^{\circ} 8$, donde la inscripción aparece en una zona rectangular rebajada unos $\mathrm{cm}$ respecto al resto de la cara frontal del soporte, y n. ${ }^{\circ} 17$, donde aparece encuadrada por una línea simple y en una zona algo rebajada. En ambos casos parece que poseyeron una inscripción previa que luego se borró para inscribir otra.

Más de la mitad de las inscripciones presentan interpunciones en forma de triángulo o de triángulo invertido, mientras que en menor medida podemos observar alguna en forma de virgula o, incluso, como un simple punto. Por otro lado, la presencia de hederae como elemento de interpunción se ha documentado tanto entre los soportes más tempranos (n. ${ }^{\text {os }} 10 \mathrm{y}$ 11 de Porcuna) como en tres de los soportes más tardíos (los n.os 31, 32 y 33, todos ellos pertenecientes a una misma casa y dedicados por la misma persona en Écija).

La ordinatio responde siempre a una disposición centrada, y en la mayoría de los casos se puede observar una gradatio descendente en el tamaño de las letras, de forma que la primera línea, que suele albergar el nombre del homenajeado, queda enfatizada. Esto es coherente con el uso honorífico de este tipo de monumentos, en el que el nombre del personaje principal tiende no solo a estar en posición inicial y preeminente sino a quedar bien visible con sus letras a modo de rótulo didascálico de la imagen que sustenta.

\section{El formulario}

Si pasamos a analizar el formulario de estas inscripciones, en primer lugar, vemos que los verbos utilizados suelen encontrarse en posición final, normalmente en la última línea de la inscripción, separados del resto del texto. Las formas más usadas son dant y dederunt, con las variaciones de suo dat o de suo dederunt, donum dat o de sua pecunia dat; la fórmula dedit solo se ha documentado en las tres inscripciones hermanas de Astigi (n. ${ }^{\text {ss }} 31,32$ y 33). Por otra parte, es destacable la pieza $n .^{\circ} 7$, en la que aparece la fórmula hic situs est, lo que permite identificarlo como la única inscripción funeraria de todo el conjunto (Saquete y Velázquez 1997) (ver figura 12). Hay que mencionar, no obstante, que 12 de las 40 inscripciones no presentan verbo, lo que enfatiza, si cabe, la función didascálica del rótulo con el nombre de los homenajeados.

En los soportes hermaicos son comunes abreviaturas de tipo posesivo, como $n$ (ostro) o $n$ (ostrae),

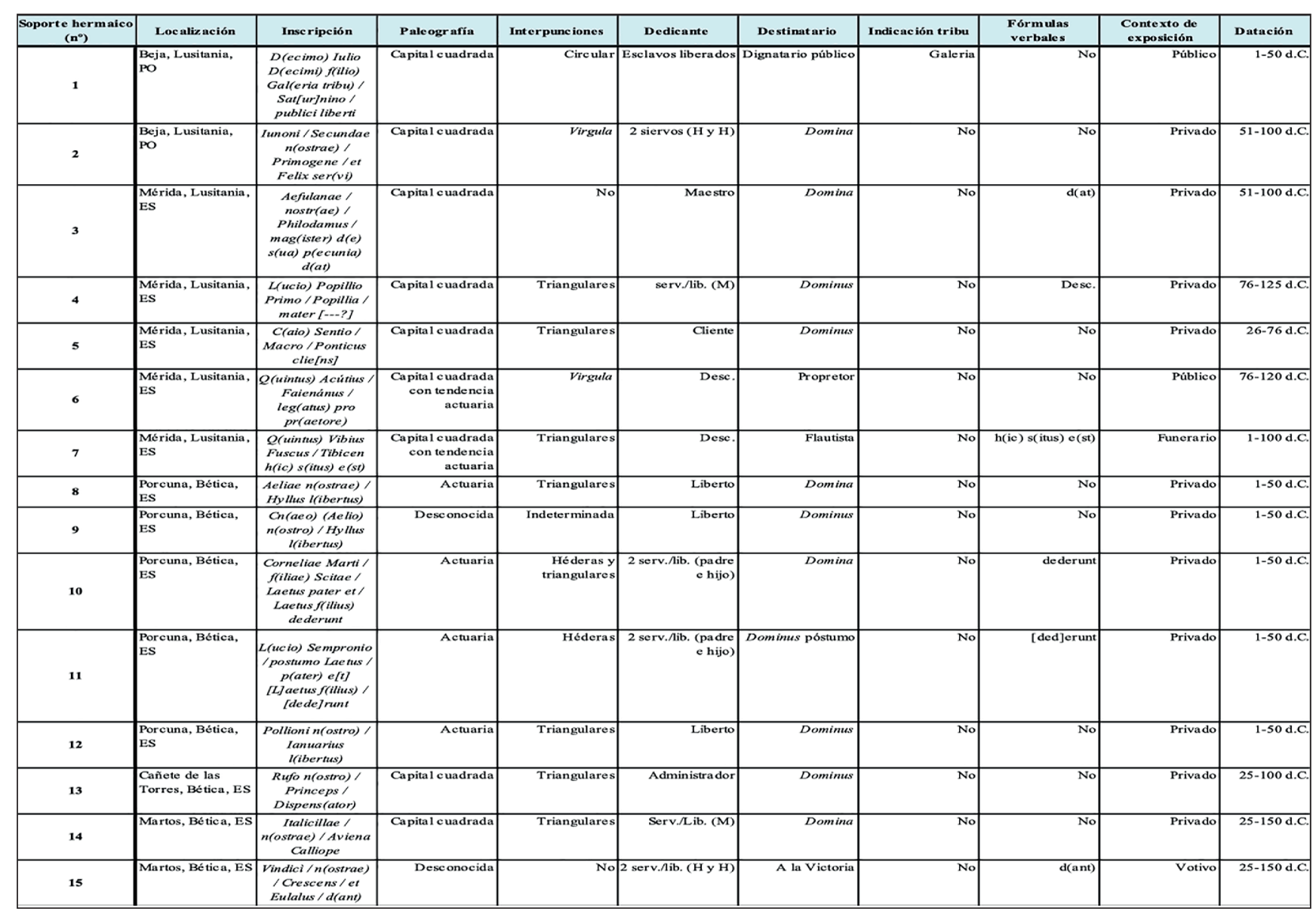

Figura 12 (12.1, 12.2 y 12.3). Cuerpo epigráfico de los soportes hermaicos hispanos. 


\begin{tabular}{|c|c|c|c|c|c|c|c|c|c|c|}
\hline \begin{tabular}{|c}
$\begin{array}{c}\text { Soporte he rmaico } \\
\left(\mathbf{n}^{\circ}\right)\end{array}$ \\
\end{tabular} & Localización & Inscripción & Paleografía & Interpunciones & Dedic ante & Destinat ario & Indicación tribu & $\begin{array}{c}\text { Fórmulas } \\
\text { verbales }\end{array}$ & $\begin{array}{c}\text { Contexto de } \\
\text { exposición }\end{array}$ & Datación \\
\hline 16 & $\begin{array}{l}\text { Montoro, Bética, } \\
\text { ES }\end{array}$ & \begin{tabular}{|c|} 
Lucretia / Grata \\
Principis (uxor)
\end{tabular} & Desconocida & No & Indet. & Domina & No & No & Dese. & $1-130$ d.C. \\
\hline 17 & $\begin{array}{l}\text { Alcolea, Bética, } \\
\text { ES }\end{array}$ & \begin{tabular}{|c|} 
L(ucius) Vale rius \\
Celtiber / A(ulus) \\
Albanius Ianuarius \\
/ de suo dederunt \\
// D(---)
\end{tabular} & $\begin{array}{r}\text { Capital cuadrada } \\
\text { con tendenc ia } \\
\text { a ctuaria }\end{array}$ & Triangulares & 2 serv./lib. (H y H) & Desc. & No & \begin{tabular}{r|} 
de suo dederunt \\
d $(---)$
\end{tabular} & Desc. & $150-200 \mathrm{~d} . \mathrm{C}$. \\
\hline 18 & $\begin{array}{l}\text { Córdoba, Bética, } \\
\text { ES }\end{array}$ & $\begin{array}{l}\text { Calpurniae / } \\
\text { Tertullae / } \\
\text { Secundina et } \\
\text { Rufina/Rufini } \\
\text { f(iliae) d(ant) }\end{array}$ & $\begin{array}{r}\text { Capital cuadrada } \\
\text { con tendencia } \\
\text { a ctuaria }\end{array}$ & Triangulares & $\begin{array}{r}\text { serv./ib. (M y } \\
\text { M) }\end{array}$ & Domina & No & $d(a n t)$ & Privado & $51-100$ d.C. \\
\hline 19 & $\begin{array}{l}\text { Córdoba, Bética, } \\
\text { ES }\end{array}$ & $\begin{array}{c}\text { Lolliae C(ai) } \\
\text { f(iliae)/ } \\
\text { Manlianae } \\
\text { n(ostrae) /A(ulus) } \\
\text { Fannius Speudon/ } \\
\text { et Voltilia Ni[ce]/ } \\
\text { d(onum) d(at) }\end{array}$ & $\begin{array}{r}\text { Capital cuadrada } \\
\text { con tendenc ia } \\
\text { a ctuaria }\end{array}$ & $\begin{array}{r}\text { Triangulares y } \\
\text { aspas (1.1) }\end{array}$ & $\begin{array}{r}2 \text { serv./ib. ( } \begin{array}{r}\mathrm{H} y \\
\mathrm{M})\end{array}\end{array}$ & Domina & No & $d$ (onum) $d(a t)$ & Privado & $100-150 \mathrm{~d} . \mathrm{C}$. \\
\hline 20 & $\begin{array}{l}\text { Córdoba, Bética, } \\
\text { ES }\end{array}$ & \begin{tabular}{|c|} 
Nicei in (ostrae) $)$ \\
Agilio ser(vus) \\
d(onum) d(at)
\end{tabular} & Capital cuadra da & Triangulares & Siervo & Domina & No & $d$ (onum) $d(a t)$ & Privado & $100-150 \mathrm{~d} . \mathrm{C}$. \\
\hline 21 & $\begin{array}{l}\text { Córdoba, Bética, } \\
\text { ES }\end{array}$ & $\begin{array}{c}\text { COJptatae } \\
\text { n(ostrae)/[--- } \\
\text { Jnianus/---- }\end{array}$ & Capital cuadra da & Indeterminada & Serv./lib. (H) & Domina & No & Dese. & Privado & $51-100$ d.C. \\
\hline 22 & $\begin{array}{l}\text { Córdoba, Bética, } \\
\text { ES }\end{array}$ & \begin{tabular}{|c} 
L(ucio) Stertinio \\
L(uci) f(ilio) / \\
Hor(atia tribu) \\
Maxumo/ \\
P(ublius) \\
Cornelius \\
Philloclis \\
l(ibertus) Auctus
\end{tabular} & Capital cuadra da & Triangulares & Liberto & Dominus & Horatia & No & Privado & $51-100$ d.C. \\
\hline 23 & $\begin{array}{l}\text { Córdoba, Bética, } \\
\text { ES }\end{array}$ & \begin{tabular}{|c|}
$L(u c i o)$ Acilio \\
L(uci) f(ilio) \\
Modesto / Felix \\
disp(ensator) d(e) \\
s(ua) p(ecunia) \\
\end{tabular} & Actuaria & Indeterminada & Administra dor & Dominus & No & $\begin{array}{l}\mathrm{d}(\mathrm{e}) \mathrm{s}(\mathrm{ua}) \\
\mathrm{p}(\text { ecunia) }\end{array}$ & Privado & $1-150$ d.C. \\
\hline 24 & $\begin{array}{l}\text { Córdoba, Bética, } \\
\text { ES }\end{array}$ & $\begin{array}{l}\text { Q(uinto) Herennio } \\
\text { /Rufo/Montanus } \\
\text { Rufif(litius) } \\
\text { contrib(ulis) d(at) }\end{array}$ & Desconocida & Indeterminada & $\mathrm{H}$ ijo & Dominus & $\begin{array}{r}\text { Indica la } \\
\text { pertenencia mutua } \\
\text { a una misma tribu }\end{array}$ & $d$ (at) & Privado & $1-200$ d.C. \\
\hline 25 & $\begin{array}{l}\text { Córdoba, Bética, } \\
\text { ES }\end{array}$ & \begin{tabular}{|c|} 
C(aio) n(ostro) $)$ \\
Princep $[$ s $] /$ \\
vilicus
\end{tabular} & Capital cuadra da & Circular & Capataz & Dominus & No & No & Privado & $31-200$ d.C. \\
\hline 26 & $\begin{array}{l}\text { Peñaflor, Bética, } \\
\text { ES }\end{array}$ & $\begin{array}{c}\text { T(ito) n(ostro) I } \\
\text { Emeritus } \\
\text { l(ibertus) d(at) }\end{array}$ & Capital cuadra da & Virgula & Liberto & Dominus & No & d(at) & Privado & $1-50$ d.C. \\
\hline 27 & Sevilla, Bétic a, ES & \begin{tabular}{|c|} 
Caciae n(ostrae) \\
Lucius) \\
Sempronius $/$ Sula \\
pecunia] dat
\end{tabular} & Capital cuadra da & Triangulares & Serv./ib. (H) & Domina & No & $\begin{array}{r}\text { s[ua pecunia] } \\
d(\text { at })\end{array}$ & Privado & $31-70$ d.C. \\
\hline
\end{tabular}

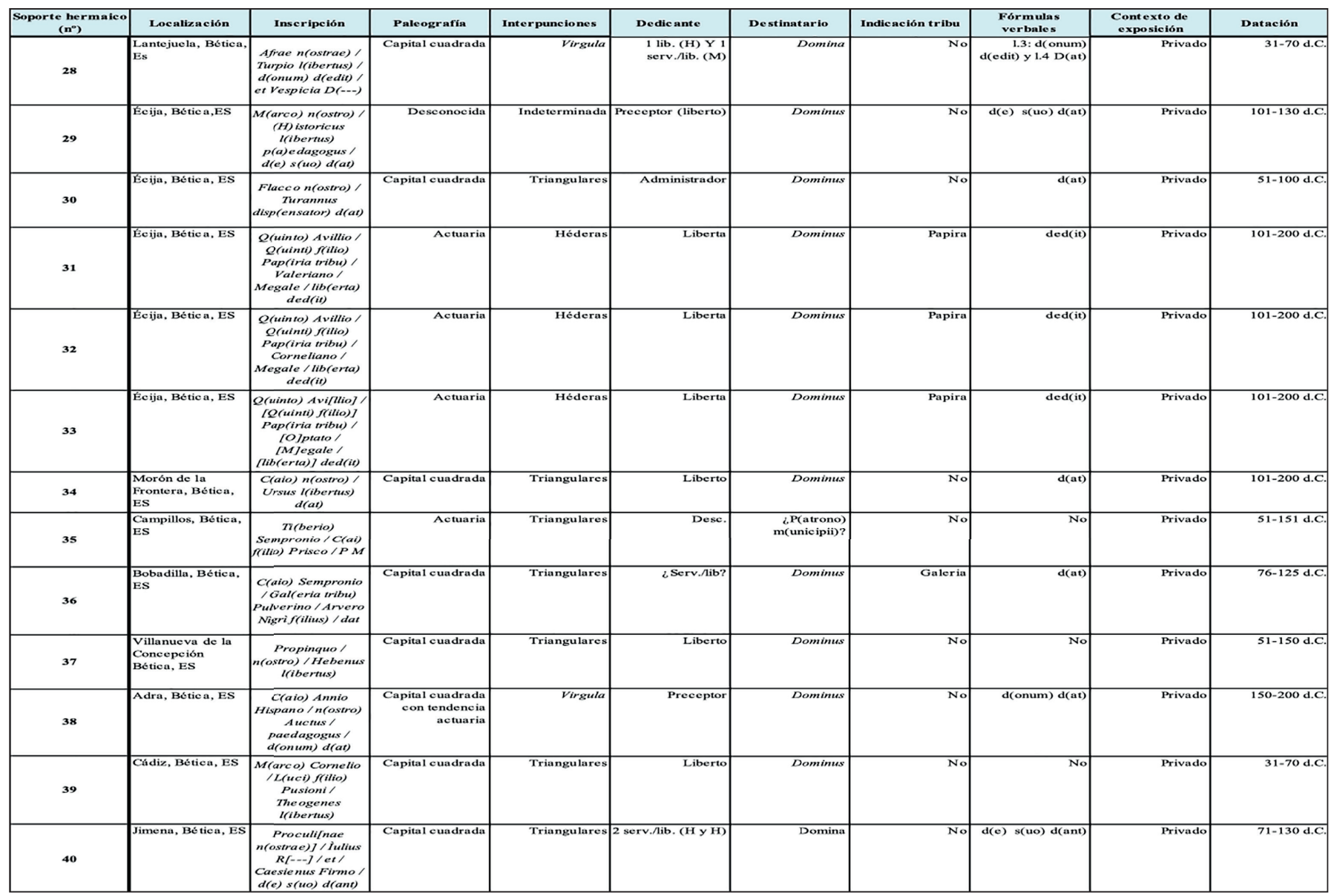

Figura 12 (12.1, 12.2 y 12.3). Cuerpo epigráfico de los soportes hermaicos hispanos. 
que además de funcionar como marcadores de afecto también son marcadores de subordinación o pertenencia a un patrono.

Respecto a los casos sintácticos, podemos observar como los nombres de los dedicantes aparecen siempre en nominativo y los homenajeados, en dativo, siguiendo la praxis habitual de los textos honoríficos. Solo tres de las inscripciones documentadas quedan fuera de esta generalidad, donde el nombre de la persona representada aparece en nominativo -en dos de ellas, además, aparece el cargo o la condición social que ostentaba el personaje retratado-. Estos casos confirman de modo evidente su carácter de rótulos didascálicos. En la mayor parte de los textos inscritos el dedicante apunta su condición social, normalmente indicando si son libertos o siervos, pero también se documentan otros casos en los que aparece su profesión o su relación con el homenajeado. Son destacables aquellas inscripciones en las que se indica las tribus del personaje representado, lo cual tiene el fin de remarcar el origen itálico de estos personajes, como son los casos de los hermae n. ${ }^{\circ} 22$, dedicado a un personaje de la tribu Horatia, y de los n.os 31,32 y 33 dedicados a un personaje de la tribu Papira.

En cuanto a la relación entre destinatarios y sus dedicantes, se constata cómo la gran mayoría son libertos dedicando el soporte a sus antiguos patronos. En estos casos, es posible pensar que estamos ante personas de una cierta importancia social, pero no podemos determinar si ejercieron algún cargo público, a no ser que se indique lo contrario. No obstante, tenemos ciertas excepciones a esta tónica general, como es el caso del herma $\mathrm{n}^{\circ}{ }^{\circ}$, en el que el homenajeado es un dignatario de la ciudad, el n. ${ }^{\circ} 6$, en el cual se representa a un legado propretor, y el n. ${ }^{\circ} 15$, de carácter votivo, en el que los libertos dedican el herma a Vindex por su liberación.

Atendiendo al contenido expreso de las dedicaciones, se puede inferir cómo la mayoría pertenecieron a un ámbito público, pero dentro de las domus o villae privadas, y fueron dedicadas por los sirvientes o esclavos a sus patronos. Aunque tenemos ciertas excepciones:

- En el n. ${ }^{\circ}$ 1, observamos cómo los libertos públicos se lo dedican a Decimus Iulius. Podemos ver en los dedicantes a los antiguos esclavos de la colonia Pax Iulia, liberados por Iulius Saturninus durante su mandato como dignatario en la ciudad. Aunque el monumento seguramente fuera exhibido en la casa del homenajeado, el motivo del homenaje seguramente tuvo que ver con el hecho de que Decimus Iulius ejerció algún cargo público, a cuyo servicio pudieron estar los libertos de Pax Iulia que, agradecidos, le dedican el herma. ${ }^{23}$

- El n. ${ }^{\circ}$ 6, que se dedica a Q(uintus) Acutius Faienanus por su forma didascálica y la calidad

23. Un paralelo de este fenómeno sería la epigrafía "pública" que se exhibe en la pars urbana de las villas, como demuestra, por ejemplo, el estudio de las inscripciones del ager Tarraconensis, especialmente los pedestales honoríficos hallados en las mismas (cf. Gorostidi 2010: 44-45; Gorostidi 2017a). de legatus propraetore de su homenajeado, así como el lugar en el que fue hallado, en el teatro romano de Mérida, parece que fue expuesto en un lugar puramente público.

- El n. ${ }^{\circ}$ 7, dedicado al flautista Q(uintus) Vibius Fuscus, presenta un carácter funerario, como indica la fórmula hic situs est, lo cual hace pensar a priori que fue expuesto en alguna zona de enterramientos (Saquete y Velázquez 1997).

- Por último, el n. ${ }^{\circ}$ 15, cuyo texto según Stylow (Portillo, Rodríguez y Stylow 1985) es Vindicì / n(ostrae) / Crescens / et Eulalus / d(ant), aunque otros (González y Marín 1985) leen N(emesi) en lugar del posesivo. Sea una opción u otra, parece en cualquier caso presentar un carácter votivo, debido a que, por un lado, el epíteto Vindex acompaña comúnmente a la diosa Némesis y, por otro, al hecho de que su culto tuvo un gran arraigo en la Bética. ${ }^{24}$ Existen dudas respecto al lugar de exposición, aunque seguramente debemos considerar que sería dentro de un ámbito doméstico.

Otro aspecto interesante es el género de los personajes implicados. Dejando de lado los rótulos de tipo didascálico, podemos observar cómo los hombres tienen una presencia preponderante en este tipo de soportes —siendo más de un $65 \%$ de los destinatarios y aproximadamente un $77 \%$ de los dedicantes-. Es destacable también el mayor número de dedicaciones de hombre a mujer $(23 \%)$ que de mujer a hombre $(11 \%)$, así como las pocas inscripciones honoríficas dedicadas por mujeres a mujeres, que representan solo un $6 \%$, mientras que las de hombres a hombres ascienden hasta un 54\%. Respecto a la categoría de los dedicantes, hay que destacar una clara mayoría de libertos sobre los siervos.

Con todo esto, podemos resumir las características epigráficas de los soportes hermaicos hispanos en los siguientes puntos:

1. Son textos breves, en los que mayoritariamente aparece el nombre del homenajeado junto con el de los dedicantes.

2. La mayoría poseen un carácter privado, aunque están destinados a ser admirados públicamente.

3. Los dedicantes son generalmente libertos o esclavos del honrado, los cuales hacen constar su condición social en el epígrafe -l(ibertus), serv(us) - o el oficio que desempeñan. Cuando no lo hacen, su condición se deduce por la presencia solo del cognomen o de onomástica frecuente en estos grupos sociales.

4. Suelen llevar abreviaturas de posesivos: $n$ (oster) o $n$ (ostra), que a pesar de expresar afecto sirven también para marcar la relación de los subordinados respecto a su patrono.

24. Sin duda se debió a las migraciones de esclavos y comerciantes que llegaban desde oriente. Si tenemos en cuenta la lectura de Marín, según la cual el nombre de la divinidad aparece abreviado, puede deberse a la creencia de que al ser representado así el numen la venganza de la diosa no actuaría. Por otro lado, al tratarse de un culto no oficial, podría ser una manera de esconder así el nombre de la diosa a la que se rinde el culto. 
5. Presencia de individuos de procedencia itálica, como se indica en algunos soportes con la indicación de la tribu (n. ${ }^{\text {s }} 22,31,32$ y 33 ), lo cual puede definir la existencia de descendiente inmigrados procedentes de la propia Italia.

\section{Conclusiones}

El estudio de los soportes hermaicos de Hispania nos permite, llegados a este punto, establecer unas conclusiones generales sobre su elaboración, contexto de exhibición, función y distribución.

En el ámbito hispano la erección de soportes hermaicos tiene una difusión, como hemos visto, muy limitada geográfica - Augusta Emerita, Pax Iulia y el valle del Guadalquivir- y cronológicamente - siglos i y II d. C.- - Esto se debe a la condición de la sociedad dentro de la cual aparecen, normalmente comunidades de militares retirados que habitan en colonias de derecho latino fundadas a principios del siglo I d. C. Entre estos grupos de veteranos, los de mayor rango serían los que estuvieron representados sobre estos soportes. Sus libertos, en calidad de dedicantes, deberían poseer una capacidad económica bastante alta dentro de este grupo de sirvientes, ya que los hermae estaban financiados por ellos.

Además, podemos deducir, en algunos casos, un origen itálico de las personas representadas, ya que así nos lo indican varios soportes. Las primeras comunidades que habitaron estas ciudades tras su fundación coinciden con el momento en el que se erigen los primeros ejemplares en Hispania. Esto parece quedar confirmado gracias al estudio de los modelos de difusión, donde vemos como el modelo que llega a Hispania es una copia del modelo usado en la zona de la Campania, lugar del que procederían gran parte de los veteranos que pasaron a poblar las colonias hispanas, principalmente en la Bética y la Lusitania.

Gracias a los soportes hallados in situ, así como a sus paralelos itálicos y galos, podemos inferir para estos soportes un contexto generalmente doméstico, mayoritariamente en domus urbanas, pero no podemos descartar también un emplazamiento en ámbito suburbano o rural, ya que algunas de las piezas documentadas en la Bética parecen haber estado en zonas extramuros o incluso en villas rurales. Estamos, por tanto, ante un soporte epigráfico-escultórico que generalmente tuvo una funcionalidad honorífica dentro del ámbito doméstico, aunque, como hemos podido ver, existen casos en los que esta tipología tuvo otras funciones -funeraria, honorífica pública, votiva-.

La importancia que llegaron a adquirir estos soportes queda atestiguada también gracias a la identificación de los materiales en los que se realizaron. En este estudio hemos podido documentar soportes hermaicos hechos en materiales procedentes de las canteras del Anticlinal de Estremoz y de Trigaches en la Lusitania, y del Torcal de Antequera / surco intrabético, Alconera / Rodadero de los Lobos y Peñaflor en la Baetica. Aunque sus áreas de influencia derivan del ámbito geográfico donde se encontraban estas explotaciones y los momentos en los que produjeron bloques para pilares hermaicos son variables, sí las podemos considerar de forma conjunta en cuanto que todas produjeron módulos que fueron utilizados como soportes de hermae.

Como se ha podido comprobar, el marmor procedente de Anticlinal de Estremoz solo se utiliza para la confección de pilares de herma en el ámbito de Augusta Emerita, mientras que el marmor de Trigaches se aplica en la realización de los soportes de Pax Iulia. Por otro lado, los marmora de la Baetica usados en la creación de estos soportes se distribuyen de manera más o menos aleatoria por todo el valle del Guadalquivir, debido, quizás, tanto a su cronología como a la demanda de un material u otro por parte de las élites locales.

Esta tendencia obliga a hablar de un mercado de carácter regional que, en ocasiones, tiene un radio de acción de hasta más de $200 \mathrm{~km}$. Las características físicas concretas de cada uno de estos materiales locales, todos con un fuerte carácter ornamental y dotado de ciertas cualidades cromáticas, harían que fueran elegidos por el mercado de nivel provincial para determinados usos según los diferentes litotipos. Estamos, por tanto, ante un comercio paralelo al de los "lujosos" mármoles orientales, pero con una dispersión más acotada.

En la provincia Baetica los soportes hermaicos se realizaron sobre calizas de tonos rojizos, púrpuras y rosados, mientras que en la Lusitania se prefieren soportes de colores blancos o blancos-grisáceos. En el último caso esto está justificado por el tipo de materiales explotados en la zona, mientras que en la Bética parece deberse más bien a modas regionales.

Si se pone en relación los materiales junto a las diversas variaciones en el formato podemos hablar de cuatro talleres diferenciados, donde se realizarían los encajes sobre los bloques extraídos de las canteras, uno en Augusta Emerita, otro en Pax Iulia, otro en Astigi y otro más en la zona de Corduba - Obulco.

Las officinae lapidariae son mucho más complicadas de reconocer, ya que la evolución cronológica produce cambios en la paleografía. Por esta razón, solamente podemos identificar grupos procedentes de un taller en un mismo momento cronológico, como ocurre con el caso de los soportes hermaicos localizados en "la casa de los hermae" de Astigi -n ${ }^{\circ s} 31,32$ y 33-.

Desde el punto de vista epigráfico hemos visto cómo los homenajeados y los dedicantes, en su mayoría libertos, son personajes de una cierta importancia social.

Por último, la mención de las tribus de origen itálico de ciertos personajes, puede ser un elemento a tener en cuenta a la hora de valorar el papel de los hermae para estos ciudadanos de las ciudades béticas y lusitanas. Los descendientes de los primeros colonos reivindicaban de esta forma su abolengo romano, escogiendo soporte honorífico y de autorepresentación que servía para enfatizar su conexión itálica. ${ }^{25} \mathrm{El}$ empleo de un monumento honorífico característico de la ornamentación doméstica centroitálica y campana sin duda funcionó para este menester, tal como

25. cf. Alföldy 2014: 16-17 (= Gorostidi 2017b: 387-388), sobre el sentimiento de orgullo de los habitantes de la colonia de Italica (Santiponce, Sevilla). 
parece confirmar el hecho de que el momento de su máxima producción sea en los primeros siglos del imperio, cuando se produjo el mayor asentamiento de veteranos e inmigrantes itálicos y las ciudades se adaptaban a los usos y gustos de Roma.
Laura Galán Palomares Institut Català d'Arqueologia Clàssica (ICAC) lgalan@icac.cat

Rebut: 19/11/2018

Acceptat: 07/03/2019

\section{Bibliografía}

AlföLdy, G. (1991). Augusto e le iscrizioni: tradizione ed innovazione. La nascità dell'epigrafia imperiale. Scienze dell'Antichità. Storia, Archeologia, Antropologia, 5: 573-600.

Álvarez, A. et alii (2009). Marbles and Stones of Hispania: Exhibition Catalogue. Institut Català d'Arqueologia Clàssica. Tarragona.

Andreu, J. (2011). Los marmora de Lusitania: su uso como soporte epigráfico. En: V. García-EnTERo (ed.). El marmor en Hispania: explotación, uso y difusión en época romana (Actas del I Coloquio de Arqueología de Carranque. Los marmora romanos en Hispania, Carranque 2009). Murcia: 297-312.

Beard, M., North, J. y Price, S. (1998). Religions of Rome: Volume 1, a History. Cambridge University Press. Cambridge.

Beltrán Fortes, J., Ontiveros Ortega, E., Loza AzuaGA, L. y Mañas Romero, I. (2012). Study and petrographic characterisation of the limestones used in roman times from the western region of the - surco intrabetico, in the present-day province of Málaga (Spain). En: A. Gutiérrez García-M., P. Lapuente e I. RoDÀ (eds.). Interdisciplinary studies on ancient stone: proceedings of the IX ASMOSIA Conference (Tarragona 2009). Institut Català d'Arqueologia Clàssica. Tarragona: 500-510.

Beltrán Fortes, J. y Rodríguez, O. (2010). Los materiales lapídeos de la provincia Baetica: estado de la cuestión y líneas actuales de investigación. En: S. Camporeale, H. Dessales y A. Pizzo (eds.). Arqueología de la construcción II, Los procesos constructivos en el mundo romano: Italia y las provincias orientales. Anejos de AEspA LVII. CSIC. Madrid-Mérida: 555-570.

Cisneros Chunchillos, M., Gisbert Aguilar, J. y Somovilla DE Miguel, I. A. (2011). El uso del mármol en la arquitectura de Asturica Augusta. Anales de Arqueología Cordobesa, 21: 101-134.

Colodrero, A. M. (2006). Evidencias de una primera monumentalización de la Colonia Augusta Firma Astigi (Écija). Rómula, 5: 113-148.
Corrales, P. (2002). El ámbito doméstico como espacio de culto. Baetica Estudios de Artes, Geografía e Historia, 23: 263-274.

Dupré, X. (2004). Las capitales provinciales de España II. Mérida. Colonia Augusta Emerita. L'Erma di Bretschneider. Roma.

Dwyer, E. (1991). The Pompeian atrium house in theory and practice. En: K. GAZDA (ed.). Roman art in the private sphere. University of Michigan Press. Michigan: 25-48.

Encarnação, J. D. (1984). Inscricões romanas do Conventus Pacensis: Beja. Coímbra.

FABiÃo, C. (2014). La Lusitania: una Provincia romana atlántica. Actas del XVIII Congreso Internacional Arqueología Clásica, vol. 2: 1657-1664.

Fusco, A. y Mañas Romero, I. (2006). Mármoles de Lusitania. Museo Nacional de Arte Romano. Mérida.

García-Dils, S. (2009). El urbanismo de la Colonia Augusta firma: una visión de conjunto a partir de los resultados de las excavaciones arqueológicas en la Plaza de España. En: J. González y P. PAvón TorreJóN (eds.). Andalucía romana y visigoda. Ordenación y vertebración del territorio. L'Erma di Bretschneider. Roma: 99-126.

García-Dils, S., Ordóñez Agulla, S. M., Conlin Hayes, E., Saquete Chamizo, J. C. y Sáez Fernández, P. (2006). La casa de los Hermae de Astigi. Habis, 37: 349-360.

Gavel, S. (2011). Placing paniskoi herms within Augustan propaganda at Pompeii. Journal of Roman Archaeology, 24, 1: 191-214.

González Román, C. y Marín Díaz, M. A. (1985). Inscripciones romanas inéditas de la provincia de Jaén. I. Cuadernos de Prehistoria y Arqueología de la Universidad de Granada, 10: 449-462.

González, J. y Saquete Chamizo, J. C. (eds.) (2011). Colonias de César y Augusto en la Andalucía romana. L'Erma di Bretschneider. Roma. 
Gorostidi, D. (2010). Ager Tarraconensis 3. Les inscripcions romanes (IRAT), Documenta, 16. Institut Català d'Arqueologia Clàssica. Tarragona: 44-45.

Gorostidi, D. (2017a). Memoria, prestigio y monumento: los pedestales de los viri flaminales en Tarraco y su difusión en ámbito provincial. En: RuIz GutiÉRREz, A. e Iglesias, J. M. (eds.). Coloquio Internacional Monumenta et Memoria. Estudios de Epigrafía Romana (Santander, 22-23 de septiembre de 2016). Edizioni Quasar. Roma: 167-187.

Gorostidi, D. (ed.) (2017b). Géza Alföldy. Estudios tarraconenses, Universidad Rovira i Virgili e Institut Català d'Arqueologia Clàssica. Tarragona.

Gutiérrez Deza, M. I. (2012). Notes on local Stone use in Colonia Patricia Corduba (Córdoba, Spain). En: A. Gutiérrez García-M., P. Lapuente e I. RodÀ (eds.). Interdisciplinary studies on ancient stone: proceedings of the IX ASMOSIA Conference (Tarragona 2009). Institut Català d'Arqueologia Clàssica. Tarragona: 493-499.

JAILLARD, D. (2001). Le pilier hermaïque dans l'espace sacrificiel. Mélanges de l'Ecole française de Rome. Antiquité, 113: 341-363.

Lamberto, V. y SÁ Caetano, P. (2009). Marble stones from Lusitania: the quarries of the Estremoz Anticline. En: Nogales, T. y Beltrán Fortes, J. (eds.). Marmora Hispana: explotación y uso de los materiales pétreos en la Hispania Romana. L'Erma di Bretschneider. Roma: 470-481.

Lapuente, P., Nogales-Basarrate, T., Royo, H. y Brilli, M. (2014). White marble sculptures from the National Museum of Roman Art (Mérida, Spain): sources of local and imported Marbles. European Journal of Mineralogy, 26 (2): 333-354.

López Medina, M. J. (1996). El municipio romano de Abdera. Una aproximación histórica. Universidad de Almería. Almería: 191-199.

Loza Azuaga, M. L. y Beltrán, J. (2011). Explotación y uso de calizas ornamentales de la provincia de Málaga durante época romana. En: García-EnTERo, V. (ed.). El marmor en Hispania: explotación, uso y difusión en época romana. UNED. Madrid: 257-274.

Mañas Romero, I. (2011). Marmora de las canteras de Estremoz, Sintra y Alconera: su uso y difusión. En: García-Entero, V. (ed.). El marmor en Hispania: explotación, uso y difusión en época romana. UNED. Madrid: 98-132.

Mañas Romero, I., y Fusco, A. (2009). Canteras de Lusitania: un análisis arqueológico. En: Nogales, T. y Beltrán Fortes, J. (eds.). Marmora Hispana: explotación y uso de los materiales pétreos en la Hispania Romana. L'Erma di Bretschneider. Roma: 488-522.

MaYer, M. (1999). Los hermae decorativos de pequeñas dimensiones: una nueva aproximación a los ejemplares hispánicos. En: Turcan, R., Blanc, N. y Buisson, A. (eds.). Imago antiquitatis: Religions et iconographie du Monde Romain. Mélanges offerts à Robert Tur. Boccard. París: 353-363.

Murillo, J. F. (2013). Colonia Patricia Corduba hasta la dinastía Flavia. Imagen urbana de una capital provincial. En: González Villaescusa, R. y Ruíz de Arbulo, J. (eds.). Simulacra Romae II. Rome, les capitales de province (capita prouinciarum) et la creation d'un espace commun européen: une approche archéologique. Biblioteca Virtual Miguel de Cervantes. Alicante: 71-93.

Nogales Basarrate, T., Gonçalves, J. y Lapuente, P. (2009). Materiales lapídeos, mármoles y talleres en Lusitania. En: Nogales, T. y Beltrán Fortes, J. (eds.). Marmora Hispana: explotación y uso de los materiales pétreos en la Hispania Romana. L'Erma di Bretschneider. Roma: 410-466.

Pensabene, P. (2014). I marmi antichi della Roma antica. Carocci. Roma.

Peña Jurado, A. (2000). Los Hermas en el Mundo Clásico: estado actual de la cuestión. Anales de Arqueología Cordobesa, 11: 203-216.

Peña Jurado, A. (2004). Nuevos hermas de pequeño formato de la Bética. Anales de Arqueología Cordobesa, 15: 271-289.

Peña JuRAdo, A. (2018). Representaciones militares en los hermas de pequeño formato de la Bética. En: Márouez, C., Ojeda, D. (eds.). Escultura romana en Hispania VIII. Ancian. Córdoba: 705-720, 774-781.

Pérez-Ruiz, M. (2014). Al amparo de los lares: el culto doméstico en las provincias romanas Bética y Tarraconense, CSIC. Anejos de Archivo Español de Arqueología LXVIII. Madrid.

Portillo, A. (2016). La importancia del color en la arquitectura pública romana. Testimonios del empleo de marmora y pintura en algunos templos de la Bética. Cuadernos de Arqueología de la Universidad de Navarra, 24: 289-338.

Portillo, R., Rodríguez, O. y Stylow, A. U. (1985). Portrathermen mit Inschrift im Romischen Hispanien. Madrider Mitherhausen, 26: 185-217.

Ramírez SÁdaba, J. L. (2003). Catálogo de las inscripciones imperiales de Augusta Emerita. Cuadernos Emeritenses, 21: 9-240.

Ramírez González, I., y SÁNchez Velasco, J. (1995). Epigrafía ossigitana. Anales de Arqueología Cordobesa, 6: 321-338.

RodÀ DE LlanZA, I. (2012). El comercio de los mármoles en Hispania. Historia Antiqua, 21: 85-92.

Rodrigues Gonçalves, L. J. (2007). Escultura romana em Portugal: uma arte do quotidiano. Museo Nacional de Arte Romano. Mérida. 
Rodríguez, O. (1981). Epígrafes latinos sobre pedestales hermaicos de la Bética. En: Instituto de Estudios Giennenses (eds.). Actas del I Congreso andaluz de estudios clásicos, Jaén 9 - 12 diciembre 1981. Jaén: 383-389.

Rodríguez, O. (1982). El conjunto de hermae-retratos de Obulco. Baetica, Estudios de arte, geografía e historia, 5: 133-144.

RodRíguez, O. (2009). Los marmora en el programa arquitectónico y decorativo del teatro romano de Itálica: Antiguas hipótesis, nuevas propuestas y posibles certezas a la luz de las aportaciones de los análisis de microscopía óptica de polarización. En: Nogales, T. y Beltrán Fortes, J. (eds.). Marmora Hispana: explotación y uso de los materiales pétreos en la Hispania Romana. L'Erma di Bretschneider. Roma: 233-259.

Rodríguez, O., Ordóñez, S. y García-Dils, S. (2008). La casa del oscillvm en Astigi. Algunos aspectos de su programa decorativo. HABIS, 39: 183-206.

RÜCKERT, B. (1997). Die Herme im öffentlichen und privaten Leben der Griechen. Untersuchungen zur Funktion der griechischen Herme als Grenzmal, Inschriftenträger und Kultbild des Hermes. Roderer. Regensburg.

Sáez Fernández, P., Ordóñez Agulla, S. M. y GarcíaDils, S. (2005). El urbanismo de la Colonia Augusta Firma Astigi: nuevas perspectivas. Mainake, 27: 89-112.

Saquete Chamizo, J. C., Velázouez Jiménez, A. (1997). El tibicen Q. Vibius Fuscus. Un músico en Augusta Emerita. ANAS, 10: 25-30.

Schultz, C. E. (2006). Women's religious activity in the Roman Republic. University of North Carolina Press. Chapel Hill: 124-125.

SEgura ARISTA, L. (1988). La ciudad ibero-romana Igabrum (Cabra, Córdoba). Vol. 43. Diputación Provincial. Córdoba.

Taylor, R., Ontiveros, E., Loza, M. y Beltrán, J. (2017). Marmora Lusitana en la Bética romana. Revista Digital de Arqueologia, Arquitectura y Artes, 4: 23-31.

Ventura, A. (1996). El abastecimiento de agua a la Córdoba romana II. Acueductos, ciclo de distribución y urbanismo. Universidad de Córdoba. Córdoba: 117-118. 